\title{
Formation, preservation and extinction of high-pressure minerals in meteorites: temperature effects in shock metamorphism and shock classification
}

\author{
Jinping $\mathrm{Hu}^{1,2^{*}}$ (1) and Thomas G. Sharp ${ }^{2}$
}

\begin{abstract}
The goal of classifying shock metamorphic features in meteorites is to estimate the corresponding shock pressure conditions. However, the temperature variability of shock metamorphism is equally important and can result in a diverse and heterogeneous set of shock features in samples with a common overall shock pressure. In particular, highpressure (HP) minerals, which were previously used as a solid indicator of high shock pressure in meteorites, require complex pressure-temperature-time $(P-T-t)$ histories to form and survive. First, parts of the sample must be heated to melting temperatures, at high pressure, to enable rapid formation of HP minerals before pressure release. Second, the HP minerals must be rapidly cooled to below a critical temperature, before the pressure returns to ambient conditions, to avoid retrograde transformation to their low-pressure polymorphs. These two constraints require the sample to contain large temperature heterogeneities, e.g. melt veins in a cooler groundmass, during shock. In this study, we calculated shock temperatures and possible $P-T$ paths of chondritic and differentiated mafic-ultramafic rocks for various shock pressures. These $P-T$ conditions and paths, combined with observations from shocked meteorites, are used to constrain shock conditions and $P-T-t$ histories of HP-mineral bearing samples. The need for rapid thermal quench of HP phases requires a relatively low bulk-shock temperature and therefore moderate shock pressures below $\sim 30 \mathrm{GPa}$, which matches the stabilities of these HP minerals. The low-temperature moderate-pressure host rock generally shows moderate shock-deformation features consistent with $\$ 4$ and, less commonly, S5 shock stages. Shock pressures in excess of $50 \mathrm{GPa}$ in meteorites result in melt breccias with high overall post-shock temperatures that anneal out HP-mineral signatures. The presence of ringwoodite, which is commonly considered an indicator of the S6 shock stage, is inconsistent with pressures in excess of $30 \mathrm{GPa}$ and does not represent shock conditions different from S4 shock conditions. Indeed, ringwoodite and coexisting HP minerals should be considered as robust evidence for moderate shock pressures (S4) rather than extreme shock (S6) near whole-rock melting.
\end{abstract}

Keywords: Chondrite, Martian meteorite, Shock metamorphism, High-pressure minerals

\footnotetext{
*Correspondence: jinping@caltech.edu

${ }^{1}$ Division of Geological and Planetary Sciences, California Institute

of Technology, Pasadena, CA 91125, USA

Full list of author information is available at the end of the article
}

\section{Introduction}

The study of shock metamorphism in natural samples is motivated by its usefulness for constraining planetary and terrestrial impact conditions, including the velocity, size and material of the impacting objects. High-pressure (HP) minerals have been recognized as unambiguous evidence of shock metamorphism in meteorites and terrestrial impact structures since the 
1960s (e.g. Chao et al. 1960, 1962; Binns 1967; Binns et al. 1969). In ordinary chondrites and shergottites, for instance, the presence of HP minerals, combined with mineral recrystallization and the results of shock recovery experiments, was proposed as evidence for a very high shock stage (S6) near the whole-rock melting regime (e.g. Stöffler et al. 1986, 1991), which has been widely used by meteoriticists thereafter. In this paper, we will be discussing the controversy caused by this classification. Ringwoodite, the polymorph of olivine with spinel structure, is quite commonly found in the melt veins of highly shocked ordinary chondrites and Martian meteorites and occurs as deep blue grains that provide easily recognized evidence of high shock (Stöffler et al. 1991). A variety of HP minerals, including wadsleyite, majorite, akimotoite, bridgmanite, lingunite, etc. have provided natural examples of minerals thought to be present deep in Earth's mantle (see Gillet and El Goresy 2013; Tomioka and Miyahara 2017 and references therein). Ahmed El Goresy has made a large contribution to the field of shock metamorphism and HP minerals through detailed petrographic and microanalytical studies of shocked samples and the discovery of new HP minerals (e.g. El Goresy and Chao 1976; Chen et al. 1996; El Goresy et al. 2004; Miyahara et al. 2019). Throughout his career, Professor El Goresy has been a strong proponent of using HP minerals to estimate shock pressures.

Although HP minerals provide clear evidence of high shock pressures in meteorites, their usefulness for constraining shock pressures is still debated because the pressures inferred from HP-mineral stabilities are far less than whole-rock melting and those inferred from deformational shock features and shock-recovery experiments (e.g., Stöffler et al. 1991; Sharp and De Carli 2006; Gillet and El Goresy 2013; Fritz et al. 2017).

HP minerals in shocked meteorites form by the crystallization of shock melt and by solid-state transformation of mineral fragments entrained in or in contact with shock melt (e.g. Binns et al. 1969; Chen et al 1996). Chen et al. (1996) were the first to recognize that the melt-vein crystallization assemblage, in the L6 chondrite Sixiangkou, matched the liquidus assemblage in the high-pressure melting experiments on Allende (Agee et al., 1995) and peridotite (Zhang and Herzberg, 1994). They concluded that the melt veins in Sixiangkou crystallized at 20-24 GPa and that this represented the equilibrium shock pressure for the sample. Since then, many have used shock-melt crystallization assemblages to constrain shock pressure or pressure during decompression (e.g. Sharp et al. 1997; Langenhorst and Poirier 2000; Beck et al. 2004; Ohtani et al. 2004; Xie and Sharp 2004; Xie et al 2006a, 2006b; Chen and Xie 2008; Fritz and
Greshake 2009; Miyahara et al. 2011a; Walton et al. 2014; $\mathrm{Hu}$ and Sharp 2017; Pang et al. 2016; Li and Hsu 2018 and many more), but this approach has not been universally adopted because of questions regarding the use of equilibrium phase diagrams to interpret shock pressure. Although supercooling and metastable crystallization can occur within the shock melt (Hu and Sharp 2017), the crystallization assemblages in most chondritic samples are consistent with the liquidus assemblages produced in static experiments (Zhang and Herzberg 1994; Agee et al. 1995; Herzberg and Zhang 1996; Trønnes and Frost 2002). If the shock melt remains in a liquid state after pressure release, it crystallizes a low-pressure assemblage (Xie et al. 2006b), such as olivine, orthopyroxene plus plagioclase, mostly observed in for example martian meteorites, which generally show evidence of shock pulses $(\sim 10 \mathrm{~ms})$ that are 1-2 orders of magnitude shorter than those inferred for shocked L chondrites (Langenhorst and Poirier 2000; Ohtani et al. 2004; Beck et al. 2005; Walton et al. 2014; Sharp et al. 2015;). Solid-state transformations of olivine and pyroxene only occur in association with shock melt and are strongly dependent on large temperature heterogeneities. Because of the short duration of shock-induced high-pressure pulses (milliseconds to seconds) in hypervelocity impacts, particularly for Martian meteorites (e.g. Beck et al. 2005; Walton et al. 2014; Sharp et al. 2015, 2019), the reconstructive phase transformations of the mineral constituents to their HP polymorphs must occur very quickly. Transformation temperatures close to melting are required to achieve the necessary reaction rates during the shock pulse (Xie and Sharp 2007). This explains the nearly exclusive association of HP minerals with shock-melt veins and pockets in meteorites.

Many other features are recognized as indicators of shock in meteorites, including planar fractures, planar deformation features, mosaicism, staining and recrystallization of olivine (e.g. Bauer 1979; Dodd and Jarosewich 1979; Stöffler et al. 1991; Takenouchi et al. 2019) plus blackening of silicates by disseminated metal or sulfide (e.g. Heymann 1967; Rubin, 1992; Moreau et al. 2017), maskelynite and feldspathic normal glass (e.g. Milton and DeCarli 1963; Stöffler 1984; Ferrière and Brandstätter 2015) and pervasive shock melt (e.g. Fredriksson et al. 1963; Dodd and Jarosewich 1979). The shock classification systems of Stöffler et al. $(1991,2018)$ use progressive shock effects to classify shocked meteorites as shock stages S1 (unshocked, $<5 \mathrm{GPa}$ ) through $\mathrm{S} 6$ (very highly shocked, $<75 \mathrm{GPa}$; the pressure thresholds vary with rock type) and whole-rock melting. The shock pressures needed to produce these shock effects are calibrated against shock effects observed from shock-recovery experiments (e.g. Milton and DeCarli 1963; Stöffler 1972; 
Kieffer et al. 1976; Bauer 1979; Jeanloz 1980; Ostertag 1983; Stöffler and Langenhorst 1994).

A variety of shock features, including shock melt, commonly co-exist in the so-called impact melt breccias and strongly shocked martian meteorites, which are rich in quenched impact melt and contain lithic and mineral clasts of the impacted rock. However, HP minerals are consistently absent in these melt-rich breccia and achondrite samples. This suggests that either the pressures in these samples were not sufficiently high to generate HP minerals, or the post-shock temperature was too high for the preservation of metastable high-pressure minerals (Stöffler 1974). The former is unlikely because the impact breccias (Hu 2016) and strongly shocked shergottites (Walton and Herd 2007) generally contain more pervasive mosaicism, extensive feldspar glass, silicate blackening and more melting than HP-mineral bearing S6 samples. It is more likely that the shock features and high-pressure minerals are annealed by high post-shock temperatures during slow cooling.

Unlike olivine recrystallization that can be unambiguously recovered from experimental shock at high pressure (e.g. Bauer 1979), HP minerals were first proposed and used as indicator of S6 extreme shock (Stöffler et al. 1991) because of the excessive difficulty in forming them by shock-synthesis (Stöffler 1974; Syono et al. 1981; Tschauner et al. 2009). More recently, HP minerals were excluded from a revised shock-stage scheme (Stöffler et al. 2018) because their complex formation conditions require specific $P-T-t$ paths instead of just certain shock pressure (Fritz et al. 2017). This leaves out an important source of information about shock conditions. If shock pressure alone cannot describe the formation of HP minerals, it is worth reviewing exactly what shock conditions they can constrain in a multi-parameter space. High pressures and temperatures in the shock state are necessary, but not fully sufficient, to produce observable HP minerals in shocked meteorites. Cooling of the meteorite before or during pressure release is equally important for the preservation of HP phases (e.g. Walton 2013; Hu and Sharp 2017; Sharp et al. 2019; Hu et al. 2020). The HP phases formed during the initial shock pulse are metastable at low pressure and they will be transformed back to low-density phases if the temperature is sufficiently high for retrograde back transformation after pressure release. HP minerals are only preserved if the sample cools through a critical temperature before the pressure release makes them metastable. That critical temperature is dependent on the thermodynamic stability of the mineral and on the reaction rates for back transformation (Reynard et al. 1996; Kimura et al. 2003; Hu and Sharp 2017), which sets an upper bound for the post-shock temperature of the sample. In summary, the HP phases observed in meteorites require a pressure-temperature-time $(P-T-t)$ path that involves very high shock temperatures to drive high-pressure reactions, combined with rapid thermal quench during decompression to prevent back-transformation reactions at low-pressure. An understanding of $P-T-t$ histories of HP-mineral bearing samples provide an opportunity to further constrain shock conditions in highly shocked meteorites if shock temperatures can be accurately estimated.

Overall, natural shock features, particularly HP minerals, in meteorites result from shock-induced high pressures plus complex and heterogeneous thermal histories. In this study, we calculated the bulk shock temperatures and release paths of common rocks and meteorites and use these to re-evaluate the shock conditions and $P-T-t$ paths in highly shocked chondrites and achondrites in the context of progressive shock-stage classification. We are mostly focused on the temperatures of shock metamorphism, the formation condition of HP minerals and the $P-T-t$ paths necessary for their preservation. For reviews on shock physics of geological materials, impact processes, HP mineral physics, shock stage classifications and summary of HP minerals in meteorites, the readers are referred to Melosh (1989), Stöffler et al. (1991), Sharp and DeCarli (2006), Gillet and El Goresy (2013), Asimow (2015), Fritz et al. (2017), Tomioka and Miyahara (2017) and Stöffler et al. (2018).

\section{Calculation of shock temperatures}

Since the 1950s, shock experiments have been used to obtain high-pressure equation of state (EOS) data for various materials. Commonly, those experiments measure the velocity histories of the sample material in the shock state (e.g. Goranson et al. 1955; Walsh and Christian 1955; Jones et al. 1966). The corresponding pressure and density of the shocked material can be precisely calculated with the Rankine-Hugoniot relations for a simple one-wave shock. However, the measurement of shock temperatures is more complicated and the available techniques only work for limited types of samples (e.g. Asimow 2018 and references therein). Moreover, the calculation of shock temperatures requires high order equations of state with considerable assumptions and approximations. In order to discuss the temperature effects in naturally shocked meteorites, we introduce two methods for calculating shock temperatures. The first method employs the Birch-Murnaghan and MieGrüneisen equation of state. The second method uses an integral approximation along the Hugoniot of the sample.

\subsection{Shock temperature in EOS}

Assuming the pre-shock velocity of the sample is zero, from conservation of mass, momentum and energy in 
shock state, the Rankine-Hugoniot equations can be written as:

$$
\begin{aligned}
& \rho_{\mathrm{o}} U_{\mathrm{s}}=\rho\left(U_{\mathrm{s}}-u_{\mathrm{p}}\right) \\
& \left(P-P_{\mathrm{o}}\right)=\rho_{\mathrm{o}} U_{\mathrm{s}} u_{\mathrm{p}} \\
& E-E_{\mathrm{o}}=\left(P+P_{\mathrm{o}}\right)\left(V-V_{\mathrm{o}}\right) / 2
\end{aligned}
$$

where $\rho$ is the density, $U_{\mathrm{s}}$ is the shock-wave velocity, $u_{\mathrm{p}}$ is the particle velocity, $P$ is the pressure, $V$ is the specific volume (inverse density $\rho$ ) and $E$ is the internal energy per specific volume. The subscript 0 denotes the preshock state of the sample. The Rankine-Hugoniot equations work for time-invariant systems. In the case that the sample has an initial velocity of $u, u_{\mathrm{p}}$ in Eqs. (1)-(3) needs to be replaced by $u_{\mathrm{p}}-u$. Correlations between the state functions $P, V, E, u_{\mathrm{p}}$ and $U_{\mathrm{s}}$ in the shock state are called the Hugoniot curve of the material, or simply the Hugoniot.

For a plastic wave propagating in a single-phase solid material, $U_{\mathrm{s}}$ and $u_{\mathrm{p}}$ yield an empirical linear relationship:

$$
U_{\mathrm{s}}=C_{\mathrm{o}}+s u_{\mathrm{p}}
$$

where $C_{\mathrm{o}}$ is the zero-pressure sound speed of the material and $s$ is a dimensionless factor. This form of Hugoniot is convenient because $C_{\mathrm{o}}$ and $s$ are obtained by fitting the velocity data measured in shock experiments (Table 1 ). For demonstrating the shock behavior of material, it is more straightforward to show the pressure-volume correlation (Fig. 1) calculated by Eq. (1), (2) and (4).

If the sample undergoes a phase transformation in the shock state, separate Hugoniot curves for the lowdensity and high-density phases are needed to describe the shock behavior. Porosity also complicates the shock behavior and Hugoniot of a material. In the low-pressure regime, pores are collapsed by an infinitely weak shock, leading to a gentle slope on the $\mathrm{P}-\mathrm{V}$ Hugoniot (Fig. 1). In practice, it is not uncommon for polymineralic porous rocks to have nearly linear $U_{\mathrm{s}}-u_{\mathrm{p}}$ Hugoniot (Table 1) in a wide range of pressures above the Hugoniot elastic limit (e.g. Ahrens and Gregson 1964; Anderson and Kanamori 1968; Marsh 1980; Anderson and Ahrens 1998; Sekine et al. 2008).

Although shock wave propagation can be considered as adiabatic at large spatial scales, the discontinuity between pre-shock and shock states increases the entropy of the system. Derivation of the RankineHugoniot equations show that the entropy increase along the Hugoniot is of third order (McQueen 1989). In other words, the first- and second-order pressure/ volume derivative on the isentrope and Hugoniot are the same at zero pressure. Therefore, at low pressure, the Hugoniot of a non-porous material and its isentrope are close to each other (Jeanloz 1989; McQueen 1989). To obtain the temperature on the Hugoniot, it is useful to first calculate the temperature on the isentrope and make a correction towards the Hugoniot.

To demonstrate the pressure-volume correlation of isentropic compression, the third order Birch-Murnaghan finite-strain equation of state is widely used (Jeanloz 1989) in its isentropic form:

$$
P_{\mathrm{S}}=3 K_{\mathrm{oS}} f(1+2 f)^{\frac{5}{2}}\left(1+\frac{3}{2}\left(K_{\mathrm{oS}}^{\prime}-4\right) f\right)
$$

$P_{\mathrm{S}}$ is the pressure on the principle isentrope, $K_{\mathrm{oS}}$ is the zero-pressure isentropic bulk modulus, $K_{\mathrm{oS}}{ }^{\prime}$ is the pressure derivative of $K_{\mathrm{oS}}$ and

$$
f=\frac{1}{2}\left[\left(\frac{V_{\mathrm{o}}}{V}\right)^{\frac{2}{3}}-1\right]
$$

For porous samples, the $V_{\mathrm{o}}$ and $K_{\mathrm{oS}}$ need to be the zeropressure specific volume and bulk modulus of the material in the condensed state. With the limit of zero strain (Ruoff 1967), $K_{\mathrm{oS}}$ and $K_{\mathrm{oS}}$ are obtain by

$$
\begin{aligned}
& K_{\mathrm{oS}}=C_{\mathrm{o}}^{2} \rho_{\mathrm{o}} \\
& K_{\mathrm{oS}}^{\prime}=4 s-1
\end{aligned}
$$

although with high finite strain, the effect of $K_{\mathrm{oS}}{ }^{\prime \prime}$ becomes significant and causes the $K_{\mathrm{os}}{ }^{\prime}$ to deviate from $4 s-1$ by $20 \%$ (Jeanloz 1989).

Since our goal is to determine the temperature, the total differential of entropy is written as a function of $V$ and $T$ and combined with the Maxwell's relation:

$$
\mathrm{d} S(V, T)=\left(\frac{\partial S}{\partial T}\right)_{V} \mathrm{~d} T+\left(\frac{\partial P}{\partial T}\right)_{V} \mathrm{~d} V
$$

On the isentrope, $\mathrm{d} S=0$ leads to

$$
\left(\frac{\partial S}{\partial P}\right)_{V} \mathrm{~d} T=-\mathrm{d} V
$$

Temperature and volume are two independent variables in Eq. (10). However, the solution for the differential $\mathrm{d} T$ and $\mathrm{d} V$ is difficult because pressure and entropy are two parameter $(V, T)$ variables.

To solve the differential equation, we use the wellknown Grüneisen parameter $(\gamma)$. It is a parameter to describe the thermal pressure at constant volume, by its definition: 


$$
\gamma=V\left(\frac{\partial P}{\partial E}\right)_{V}
$$

The Grüneisen parameter has the advantage of being well-approximated as a function of volume only and can be used to relate other thermodynamic parameters, e.g. $S$ and $P$ in Eq. (10). The $\gamma-V$ correlation is commonly expressed as:

$$
\gamma(V)=\gamma_{o}\left(\frac{V}{V_{o}}\right)^{q}
$$

where $\gamma_{\mathrm{o}}$ is the initial Grüneisen parameter at volume $V_{\mathrm{o}}$ and $q$ is an exponential factor. Applying the first law of thermodynamics, $\mathrm{d} E=T \mathrm{~d} S-P \mathrm{~d} V$, to Eq. (11), we get

$$
\left(\frac{\partial P}{\partial S}\right)_{V}=\frac{\gamma T}{V}
$$

The combination of Eqs. (10), (12) and (13) demonstrates that the temperature $\left(T_{\mathrm{S}}\right)$ on the isentrope at a given $V$ is solved as

$$
T_{S}=T_{o} e^{\frac{\gamma_{o}}{q}\left[1-\left(\frac{V}{V_{o}}\right)^{q}\right]}
$$

and $T_{\mathrm{o}}$ is the starting temperature.

Knowing the isentropic pressure $\left(P_{\mathrm{S}}\right)$ and temperature $\left(T_{\mathrm{S}}\right)$ at a certain volume $\mathrm{V}$, correction to the Hugoniot pressure $\left(P_{\mathrm{H}}\right)$ and temperature $\left(T_{\mathrm{H}}\right)$ at this given volume $\mathrm{V}$ can be done by solving the Grüneisen Eq. (11). We get:

$$
\Delta E_{\mathrm{V}}(V)=E_{\mathrm{H}}(V)-E_{\mathrm{S}}(V)=\frac{V}{\gamma(V)}\left(P_{\mathrm{H}}(V)-P_{\mathrm{S}}(V)\right)
$$

where $\Delta E \mathrm{v}$ is the energy difference (Fig. 1) between the system energy on the Hugoniot $\left(E_{\mathrm{H}}\right)$ and isentrope $\left(E_{\mathrm{S}}\right)$.

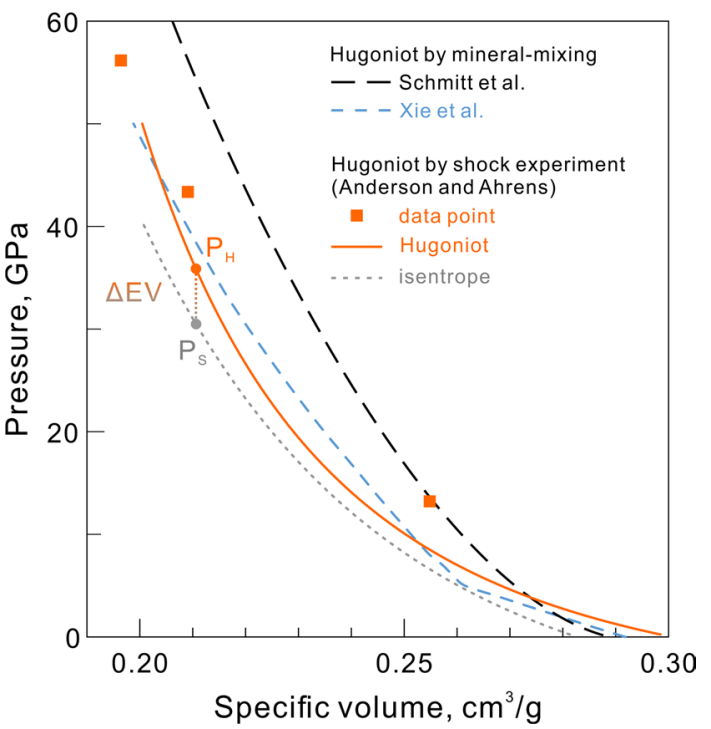

Fig. 1 Pressure-volume Hugoniots of $L$ chondrite from mineral mixing models (Schmitt et al. 1994; Xie et al. 2006b) and shock experiment (Anderson and Ahrens 1998) along with a calculated dense isentrope. $\Delta E_{V}$ is the internal energy difference between the isentropic and Hugoniot state of the same specific volume

This is referred to as the Mie-Grüneisen equation of state. Thus, the temperature on the Hugoniot is given by

$$
T_{\mathrm{H}}=T_{\mathrm{S}}+\Delta T_{\mathrm{V}}=T_{\mathrm{S}}+\frac{\Delta E_{\mathrm{V}}(V)}{C_{\mathrm{V}}}
$$

where $\Delta T_{\mathrm{v}}$ is the conceptional temperature difference

\begin{tabular}{|c|c|c|c|c|}
\hline & Kinosaki basalt $^{1}$ & Murchison $^{2}$ CM2 & Bruderheim $^{2}$ L6 & $\begin{array}{l}\text { San } \\
\text { Macros } \\
\text { Gabbro }\end{array}$ \\
\hline$\rho_{0^{\prime}} \mathrm{kg} / \mathrm{m}^{3}$ & 2700 & 2244 & 3337 & 2941 \\
\hline porosity, vol\% & $4-7 \%$ & $23 \%$ & $6-8 \%$ & - \\
\hline$K_{\mathrm{oS} \prime} \mathrm{GPa}$ & 50 & 24 & 32 & 32 \\
\hline$K_{o s}^{\prime}$ & 4.2 & 4.9 & 5.5 & 4.6 \\
\hline$\gamma_{0}$ & 1.39 & 1 & 2.00 & 1.37 \\
\hline$q$ & - & 0 & - & 0.94 \\
\hline$C_{0}, \mathrm{~km} / \mathrm{s}$ & 3.5 & 1.87 & 3.11 & 3.3 \\
\hline s & 1.3 & 1.48 & 1.62 & 1.41 \\
\hline
\end{tabular}
between the Hugoniot and isentrope at a given volume and $C_{\mathrm{V}}$ is the isochoric heat capacity defined by the temperature partial derivative of internal energy at constant volume.

Table 1 Hugoniot data for basalt, gabbro and chondrites

$\rho_{\mathrm{o}}$ : initial bulk density, $K_{\mathrm{os}}$ : zero-pressure isentropic bulk modulus, $K_{\mathrm{os}}{ }^{\prime}$ : pressure derivative of the bulk modulus, $\gamma_{\mathrm{o}}$ and $q$ : Grüneisen parameter at initial crystal density and the exponent factor, $C_{\mathrm{o}}$ and $s$ : bulk sound speed and the dimensionless parameter in the $U_{\mathrm{s}}-u_{\mathrm{p}}$ Hugoniot

${ }^{1}$ Sekine et al. (2008); ${ }^{2}$ Anderson and Ahrens (1998); ${ }^{3}$ Boslough (1984) 
As mentioned, $T_{\mathrm{S}}$ and $T_{\mathrm{H}}$ are close for condensed material at below $10 \mathrm{GPa}$ (Fig. 2). The effect of porosity in the sample will be discussed in Sect. 2.3.

\subsection{Shock temperature by integral approximation along the Hugoniot}

The application of the Birch-Murnaghan EOS requires the ability to fit the shock velocity data to the condensed isentropic bulk modulus. For a polymineralic rock of heterogeneous textures, this fitting can have considerable uncertainty if the experimental data is too limited (Fig. 1). An alternative method for estimating the shock temperature is to integrate the infinitesimal temperature change along the Hugoniot to the pressure of interest (McQueen 1989). The advantage of this method is that it makes use of the measured Hugoniot curve and does not required fitting of the data to linear $U_{\mathrm{S}}-u_{\mathrm{p}}$ correlations.

From the Hugoniot energy Eq. (3) and the first law of thermodynamics, the total differential of internal energy on the Hugoniot is

$$
\mathrm{d} E=\frac{1}{2}\left[\left(V_{o}-V\right) \mathrm{d} P-P \mathrm{~d} V\right]=T \mathrm{~d} S-P \mathrm{~d} V
$$

Using the isochoric heat capacity and Grüneisen parameter to replace the partial derivatives in Eq. (9), the differential of entropy is written as

$$
\mathrm{d} S(V, T)=\frac{C_{V}}{T} \mathrm{~d} T+\frac{\gamma C_{V}}{V} \mathrm{~d} V
$$

Substituting the $\mathrm{d} S$ in Eq. (17), we get

$$
\mathrm{d} T=-T \frac{\gamma}{V} \mathrm{~d} V+\frac{1}{2 C_{\mathrm{V}}}\left[\left(V_{\mathrm{o}}-V\right) \mathrm{d} P+P \mathrm{~d} V\right]
$$

A general solution for $T$ in this differential equation is mathematically difficult. However, in practice, we can replace the infinitesimal $\mathrm{d} V$ and $\mathrm{d} P$ by a small $\Delta V$ and $\Delta P$ on the Hugoniot (McQueen 1989). Assuming $i$ and $i-1$ are two closely adjacent points on the Hugoniot, Eq. (19) is approximated by

$$
T_{i}=\frac{T_{i-1}\left[1-\frac{\bar{\gamma}\left(V_{i}-V_{i-1}\right)}{2 \bar{V}}\right]+\frac{1}{2 \overline{C_{V}}}\left[\left(V_{o}-\bar{V}\right)\left(P_{i}-P_{i-1}\right)+\bar{P}\left(V_{i}-V_{i-1}\right)\right]}{1+\frac{\bar{\gamma}\left(V_{i}-V_{i-1}\right)}{2 \bar{V}}}
$$

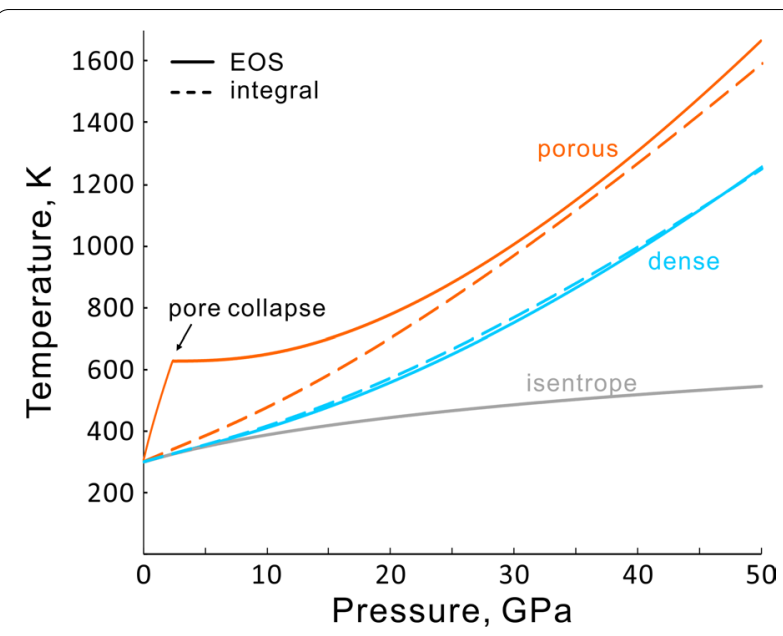

Fig. 2 The shock temperature versus pressure for porous and dense $L$ chondrite, calculated by the equation of state (EOS) and integral approximation, using the Hugoniot data in Table 1

two methods generally agree well (Fig. 2) and both give reasonable estimates of shock temperature.

\subsection{Shock temperature and porosity of chondritic and differentiated mafic rocks}

The Hugoniot of common rocks and meteorites used for temperature calculation is summarized in Table 1. The $U_{\mathrm{s}}-u_{\mathrm{p}}$ data of the Bruderheim L6 chondrite does not perfectly fit a single line (Anderson and Ahrens 1998). At 25-65 GPa, the Hugoniot seems to be a mixture of low-density and high-density phases. Also, at $\sim 13 \mathrm{GPa}$ the shock wave shows a two-wave structure, commonly interpreted as a low velocity shock wave overlapping with an elastic precursor. However, the velocity is extraordinarily high for an elastic precursor of silicate rock and, alternatively, may result from a sluggish phase transformation (Fig. 1; Anderson and Ahrens 1998). The data were not enough to fit separate Hugoniots for the phase transitions. Nevertheless, the low- and high-density Hugoniots are not drastically different, probably because either one is a combination of low- and high-density polymorphs of where the overbar denotes the mathematical average of $V, P, \gamma$ and $C_{\mathrm{V}}$ between points $i$ and $i-1$.

Unlike the $\mathrm{B}-\mathrm{M}$ equation of state, the integral approximation is not a function of the final state on the Hugoniot. Every shock temperature on the Hugoniot is important for calculating the temperature of the next points. For condensed material, the results from the

rock-forming minerals. The simplified fitted Hugoniot generally matches the data points except at low-pressure $<13 \mathrm{GPa}$ (Fig. 1). Given that, and the very limited Hugoniot data for L chondrites, we still use the linear Hugoniot that reasonably fits the HP data points for our calculation. Hugoniot of terrestrial mafic rocks, such as dunite, peridotite and gabbro do not seem to resemble 
the chondrite data in phase transition (Marsh 1980). Mineral-mixing models of chondrite can also be used to fit and interpret the Hugoniot data. A mineral-mixing model by Schmitt et al. (1994) shows a Hugoniot above the measurements. In contrast, the mixing model for Tenham L6 chondrite used by Xie et al. (2006b) and Sharp and DeCarli (2006) agrees with the fitted Hugoniot (Fig. 1). This suggests that the fitted Hugoniot and the model by Xie et al. (2006b) are likely suitable for temperature calculations.

The Grüneisen parameter of rocks is an essential part in temperature calculations. The zero-pressure $\gamma_{0}$ can be calculated by

$$
\gamma=\frac{V \alpha K_{\mathrm{T}}}{C_{\mathrm{V}}}
$$

where $\alpha$ is thermal expansion and $K_{\mathrm{T}}$ is the isothermal bulk modulus (Asimow 2015). The high-pressure $\gamma$ and exponential factor $q$ can be determined by shocking material of different initial conditions to the same volume (e.g. Luo et al. 2002). If experimental data is not available, it is reasonable to assume $q=1$, thus $\rho \gamma=\rho_{\mathrm{o}} \gamma_{\mathrm{o}}$, for solids (Asimow 2012).

The isochoric heat capacity $C_{\mathrm{V}}$ is also needed for the calculations (Eq. 16 and 20). In experiments, the isobaric heat capacity $C_{\mathrm{P}}$ is commonly measured. They have the correlation of

$$
C_{\mathrm{P}}-C_{\mathrm{V}}=T V \alpha^{2} K_{\mathrm{T}}
$$

For typical solids, the difference between $C_{\mathrm{V}}$ and $C_{\mathrm{P}}$ are on the order of $10 \mathrm{~J} / \mathrm{kg} \mathrm{K}$ (Navrotsky 1994). The pressure effect on heat capacity has not been fully investigated. Data on olivine suggest that at the pressure of interest the heat capacity decreases on the order of $10 \mathrm{~J} / \mathrm{kg} \mathrm{K} \mathrm{com-}$ pared to that of zero pressure. The measured $C_{\mathrm{p}}$ values at low pressure are in the range of $800-1400 \mathrm{~J} / \mathrm{kg} \mathrm{K}$ at 300 $3000 \mathrm{~K}$ for common rocks and silicate minerals (Watanabe 1982; Richet and Fiquet 1991; Waples and Waples 2004). We use these values for our calculations although we understand that they are somewhat different from the needed high-pressure $C_{\mathrm{V}}$.

Natural samples, other than deep intrusive rocks, have considerable initial porosity (Table 1). A porous Hugoniot can be calculated from the Hugoniot of a condensed material using the following equation (e.gAhrens and O'Keefe 1972; Tyburczy et al. 2001):

$$
P_{\mathrm{p}}=P_{\mathrm{d}} \frac{1-\frac{\gamma}{2}\left(\frac{V_{\mathrm{od}}}{V}-1\right)}{1+\frac{\gamma}{2}\left(\frac{V_{\mathrm{op}}}{V}-1\right)}
$$

where $P_{\mathrm{p}}$ and $P_{\mathrm{d}}$ are the shock pressure on porous and dense Hugoniot at volume V. $V_{\text {od }}$ and $V_{\text {op }}$ are the initial volume of dense and porous sample. We also use this equation and the Hugoniot of naturally porous samples to estimate the zero-pressure bulk modulus of the same material in the condensed state (Table 1).

Figure 1 shows the Hugoniot of a naturally porous L chondrite plus the calculated (dense) reference isentrope. The dense isentrope matches with the pore collapse volume predicted by the mineral-mixing model from Xie et al. (2006b). The corresponding shock temperatures are included in Fig. 2, calculated by the two methods introduced in Sects. 2.1 and 2.2. The temperature estimates of dense material from the two methods are close to each other. The small difference likely suggests the uncertainty of bulk modulus calculated from the simplified Hugoniot.

In contrast, the EOS calculation for a porous Hugoniot shows a temperature jump in the pore collapse regime. This is because the pore collapse by the infinite weak shock deposits large amount of energy to the system and increases the shock temperature. In the Mie-Grüneisen EOS, this process is quantitatively demonstrated by the fact that the Hugoniot pressure and isentropic pressure (infinite weak) at a given volume are significantly different for porous material (Fig. 1). Thus, the $\Delta E_{\mathrm{V}}$ and $T_{\mathrm{V}}$ in Eqs. (15) and (16) are greater than that of condensed material. The integral approximation does not show such a temperature jump because this method relies on the shape of the Hugoniot curve. The simplified Hugoniot of L chondrite (Table 1) does not include a pore-collapse transition, which is thus neglected in the temperature calculation. In the integral method, each temperature is dependent on the temperature of the adjacent point. Therefore, the underestimation of shock temperature in the pore collapse regime is propagated into the highpressure temperatures. This explains why the integral temperatures are below the EOS temperatures for the porous material. Because there is not enough data to constrain the shock behavior of a chondrite through the pore-collapse and the elastic regimes, neither of the two methods is perfectly accurate. Nevertheless, both methods provide reasonably consistent shock temperature approximations of porous materials.

Shock temperatures for common rocks calculated by the integral method, and all starting with $298 \mathrm{~K}$, are shown in Fig. 3. The Murchison CM2 chondrite has a distinctly higher porosity (Table 1 ) and therefore higher shock temperature. The $P-T$ Hugoniot crosses the chondrite liquidus at $40 \mathrm{GPa}$. For other rock types, whole-rock melting does not occur below $50 \mathrm{GPa}$, but melting may still occur locally, forming melt veins and pockets. The shock temperatures roughly increase in the sequence of $\mathrm{L}$ chondrite, dense gabbro, basalt and porous gabbro. This 
sequence agrees with increasing porosity and compressibility of these rocks. These results are consistent with results using similar calculation methods by Gillet and El Goresy (2013).

\section{Temperatures on release adiabat}

Post-shock temperature can have a significant effect on annealing high-pressure signatures in shocked meteorites (Rubin 2002, 2004; Kimura et al. 2003; Walton 2013; $\mathrm{Hu}$ and Sharp 2017; Fukimoto et al. 2020). Annealing used in the context of shock metamorphism refers to the retrograde metamorphism of shock features resulting from post-shock heating (Bauer 1979; Jeanloz 1980). The post-shock temperature for a given shock pressure can be calculated from the amount of waste heat added to the system, defined by the work from shock loading along Rayleigh-line minus the work from decompression (Schmitt et al. 1994; Sharp and DeCarli 2006). However, the final post-shock temperature is not the only important factor in the retrograde metamorphism of shock features. On the release path, a high- $T$ moderate- $P$ condition may also modify the signature of peak shock pressure (Hu and Sharp 2017). In that case, it is useful to calculate the $P_{\text {release }}-T_{\text {release }}$ path of continuous decompression.

As the release wave propagates, decompression occurs as a continuous process in a time-variant system (Asimow 2015). Several techniques are used to measure the release states in shock experiments, e.g. using a series of release buffers that have lower shock impedance than the sample to get a series of $u_{\mathrm{p}}-P$ points on the release path (Anderson and Ahrens 1998; Luo et al. 2003). The volume on the release path can be calculated with the Riemann integral

$$
V_{\mathrm{r}}=V_{\mathrm{H}}+\int_{u_{\mathrm{pH}}}^{u_{\mathrm{pr}}} \frac{\mathrm{d} u_{\mathrm{p}}}{\mathrm{d} P / \mathrm{d} u_{\mathrm{p}}}
$$

where $\mathrm{H}$ and $\mathrm{r}$ denotes the points on the Hugoniot and release path. The release adiabat is approximately isentropic so that the temperature upon decompression can be calculated with a modification of Eq. (14):

$$
T_{\mathrm{r}}=T_{\mathrm{H}} e^{\frac{\gamma\left(V_{\mathrm{H}}\right)}{q}\left[1-\left(\frac{V}{V_{\mathrm{H}}}\right)^{q}\right]}
$$

This equation is the same as (14) except the starting point is the shock state.

Anderson and Ahrens (1998) obtained three points on the release state of the Bruderheim L chondrite (Fig. 4). The data show that the sample has a higher particle velocity on the release path than that on the reflected Hugoniot. This indicates that the release volume is greater than the volume on the Hugoniot, based on the Riemann equation of release (Eq. 24). The interpretation can be that melting occurs more extensively in the sample than expected even at below $50 \mathrm{GPa}$ (Fig. 3). In this scenario, for the unmelted portion, the final release volume should only be slightly greater than the initial condensed volume. With the limited data, it is difficult to build a complete release path. Instead, we use Eq. (25) to construct a $V-T$ path of release for solid and melt. At the temperature of $500-800 \mathrm{~K}$ for the solid material, the expansion of major chondritic minerals is only on the order of $10^{-3}$ (Suzuki 1975) and we can use the initial volume as reference for release volume without making a noticeable error in the calculation of post-shock temperatures. The $P-T$ release path is constructed by comparing the release path to the Hugoniot using the Mie-Grüneisen equation:

$$
P_{\mathrm{r}}(V)=P_{\mathrm{H}}(V)+\frac{\left(T_{\mathrm{r}}-T_{\mathrm{H}}\right) C_{\mathrm{V}} \gamma}{V}
$$

where $\mathrm{H}$ and $\mathrm{r}$ denotes the points on the Hugoniot and release isentrope at volume $\mathrm{V}$. The $P-T$ release path of an L chondrite and a basalt from 25, 40 and $50 \mathrm{GPa}$ are shown in Fig. 5 and 6. The slope of release is gentle at the beginning and becomes steeper with decreasing pressure. The complete temperature drop upon release is 300 (for $25 \mathrm{GPa}$ )-900 (for $50 \mathrm{GPa}$ ) Kelvin in the bulk rock, making the post-shock temperature 500-900 K.

In meteorites, many shock features, particularly the high-pressure minerals, are associated with local shock

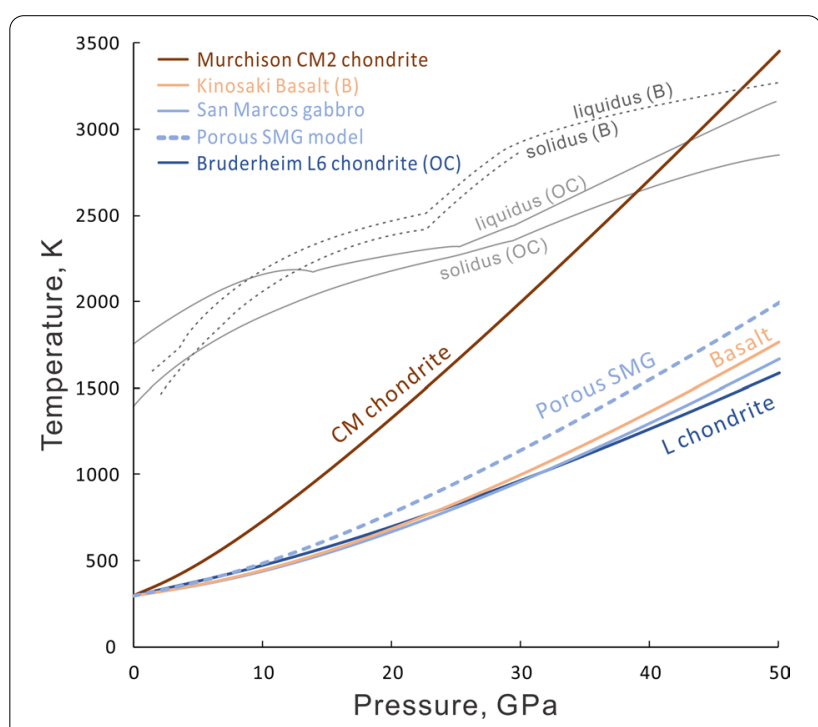

Fig. 3 The shock temperatures of common rocks and meteorites, calculated by the Hugoniot integral approximation, using the parameters in Table 1. SMG is San Marcos gabbro. The representative solidus and liquidus of ultramafic/mafic rocks are for chondrites (OC) from Agee et al. (1995) and basalt (B) from Hirose et al. (1999) and Andrault et al. (2011) 
melt (e.g. Sharp and DeCarli 2006; Tomioka and Miyahara 2017 and references therein). The $P-T$ release path of shock melt is essential for understanding the formation of shock features. However, local melting represents a deviation from the bulk Hugoniot that can be very large at modest shock pressures. In this case, it is not possible to constrain the temperature and density of shock melt vein at $<50 \mathrm{GPa}$ using the bulk Hugoniot of the rock. Qualitatively, we assume that the shock melt reaches pressure equilibrium with the bulk rock and has a shock temperature slightly higher than the liquidus for the sample (Figs. 5 and 6). In practice, the temperature of shock melt can be either significantly above the liquidus, resulting in further melting of adjacent host rock (Sharp et al. 2015), or it can be even slightly below the liquidus, because of metastable melting of low-pressure phases at high pressure.

To calculate the $P-T$ release path of shock melt, we use the Grüneisen parameter and density of melt (Table 2) for Eq. (25). We refer to the density model of peridotite melt (Asimow 2018) to represent the chondritic melt. The data for basaltic melt are taken from ab initio simulations (Bajgain et al. 2015) as it cannot be easily measured by shock experiments. The Grüneisen parameter of a liquid is very different from that of a solid and commonly has a negative exponential factor $q$ (Eq. 12; Asimow 2012). Parameters used for the calculations are listed in Table 2. The release paths from 25, 40, and $50 \mathrm{GPa}$ (Fig. 5 and 6) show a moderate temperature drop and are mostly more gentle than the lowpressure liquidus of chondrite and basalt, indicating no crystallization upon adiabatic decompression in most cases. Although the chondrite path of $25 \mathrm{GPa}$ crosses the liquidus between 4 and $13 \mathrm{GPa}$, crystallization is likely to be limited during adiabatic decompression because the release of latent heat of crystallization. For the basalt, the release path sits well above the liquidus through the pressure range (Fig. 6).

\section{Temperature effects in shocked meteorites}

Our calculations of shock and release temperatures allow for the interpretation of shock effects in meteorites in terms of pressure-temperature-time $(P-T-t)$ histories. The shocked meteorites that we will discuss include HP-mineral bearing (previously classified as S6 based on Stöffler et al. 1991) samples, partially annealed "S6" samples and melt breccias (some also represent S6) that have abundant shock melt but lack HP minerals. The $P-T$ conditions of HP-mineral formation as well as $P-T$ paths of quench and annealing are illustrated in Fig. 7. This discussion will walk through the representative samples,

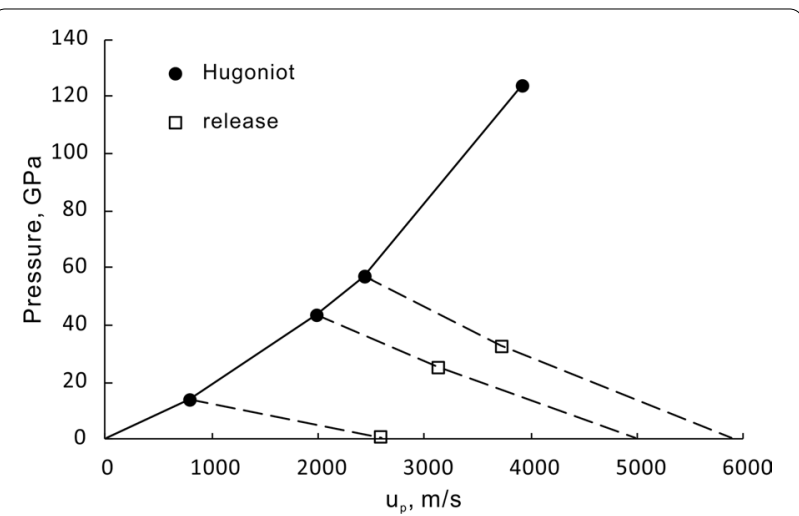

Fig. 4 Measured Hugoniot and release state of the Bruderheim L6 chondrite in particle velocity-pressure space, after Anderson and Ahrens 1998

their corresponding paths in Fig. 7 and how their pressures deviate from the actual shock stage S6.

\subsection{HP-mineral formation constraints on P-T}

The majority of high-pressure minerals in shocked meteorites are formed by melt-crystallization and reconstructive phase transformations exclusively in melt regions and are mostly used to identify the $\mathrm{S} 6$ shock stage, based on Stöffler et al. 1991. The HP-mineral assemblage in most of these samples consists of polymorphs of common silicate, oxide and phosphate minerals (Sharp and DeCarli, 2006; Gillet and El Goresy 2013; Tomioka and Miyahara 2017 and references therein). Olivine clasts, entrained in the shock melt, are commonly transformed to ringwoodite or in some cases wadsleyite (Fig. 8a-b). The transformation of enstatite to its HP polymorphs majorite, akimotoite and bridgmanite are relatively less commonly reported. Shock melt in S6 L chondrites commonly crystallizes an assemblage that contains majoritic garnet solid solutions along with ringwoodite and/ or magnesiowüstite (Fig. 8c) and in some cases bridgmanite or akimotoite. Such HP-mineral assemblages provide three major constraints on the pressure-temperature conditions of shock, as outlined in the following paragraphs.

First, the crystallization assemblages in these nominally highly shocked (S6) samples are consistent with crystallization at approximately $20-25 \mathrm{GPa}$, as indicated by static high-pressure experiments on chondritic compositions and the resulting liquidus phase-relations (Agee et al. 1995; Asahara et al. 2004). If a high-pressure crystallization assemblage in the sample is constant across the melt veins and melt pockets, it can be inferred that the pressure did not drop significantly during crystallization 


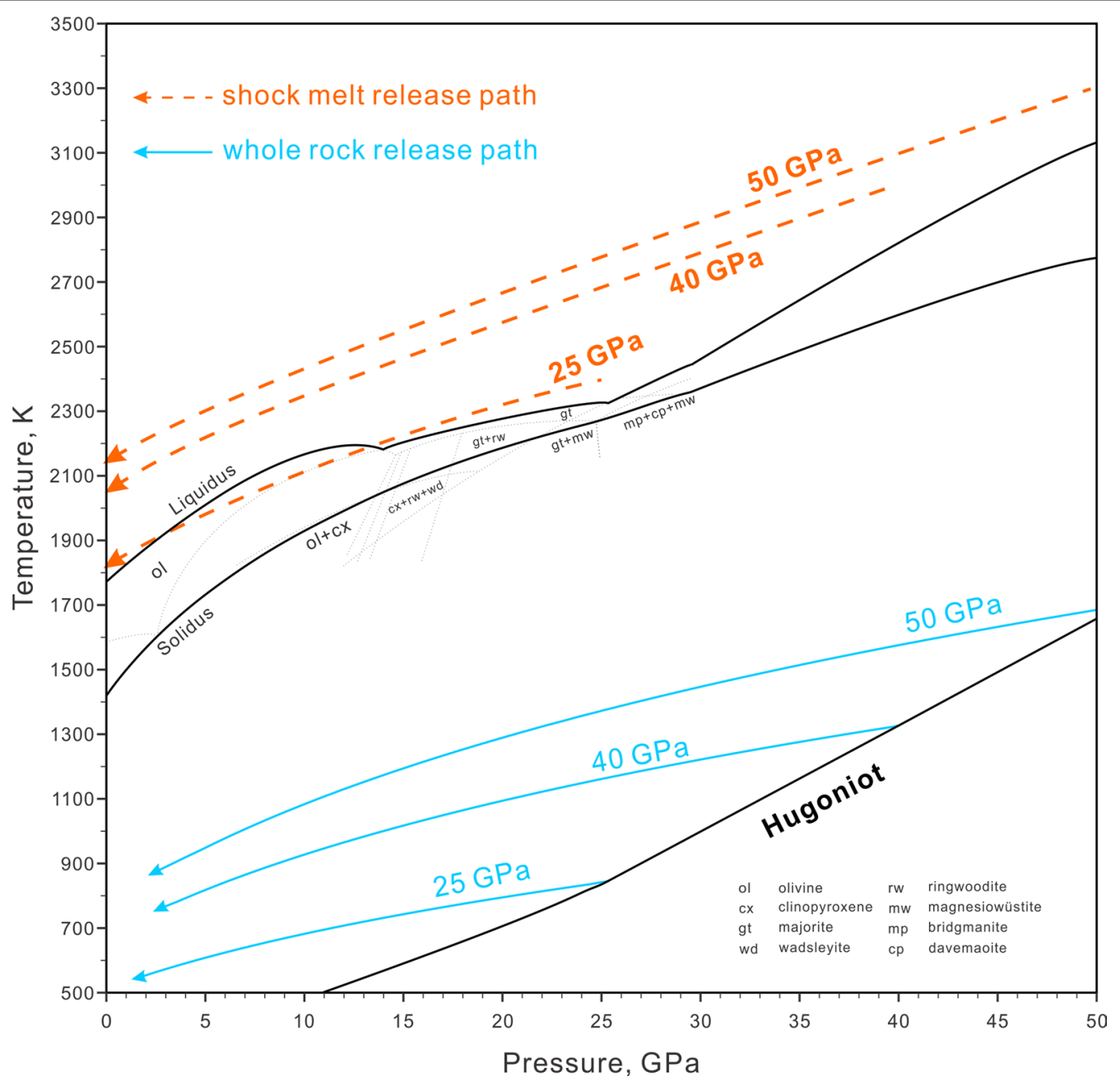

Fig. 5 The adiabatic release paths of $L$ chondrite bulk rock (cyan) and shock melt (orange) at 25, 40 and $50 \mathrm{GPa}$ superimposed on the phase diagram of Agee et al. (1995). The P-T Hugoniot of L chondrite is the same as Figs. 2 and 3. The calculation parameters are in Tables 1 and 2

and that the crystallization pressure is the equilibration shock pressure (blue curve in Fig. 7; Sharp and De Carli 2006; Miyahara et al. 2011a; Hu and Sharp 2017). A constant or nearly constant crystallization pressure implies that the sample was in the isobaric zone of the impact where the separation between the shock wave and release wave results in a period of nearly constant equilibrium shock pressure. This isobaric zone is in contrast to areas shocked by an attenuated wave, which experiences an immediate decay in shock pressure instead of an initially constant pressure (Asimow 2015; Fritz et al. 2017). If the melt matrix includes mostly wadsleyite instead of ringwoodite, such as in LL chondrite NWA 757 (Hu and Sharp 2017), the crystallization pressure is inferred to be lower than $20 \mathrm{GPa}$. Even though metastable melting and crystallization may occur, the crystallization pressure can still be constrained from the liquidus and sub-solidus phase-assemblages in the melt matrix ( $\mathrm{Hu}$ and Sharp 2017). In contrast to the long pulse of up to seconds in $\mathrm{L}$ chondrites, the relatively short pulse recorded in martian meteorites results in rapid pressure release before complete crystallization of the shock melt, leading to low-pressure crystallization assemblages and even vesiculated melt pockets (e.g. Walton et al. 2014; red melt release path in Fig. 7). It is worth noting that the short pulse does not necessarily imply small source craters on Mars. Shock dwell-time models by Bowling et al. (2020) indicate that dwell times of $10-100 \mathrm{~ms}$ are consistent with craters of 14-104 km diameter for a typical impact velocity of $13.1 \mathrm{~km} / \mathrm{s}$. Therefore, the $3-60 \mathrm{~km}$ potential meteorite-launching young $(<10 \mathrm{Ma})$ craters on Mars (Lagain et al. 2021) are consistent with relatively short 


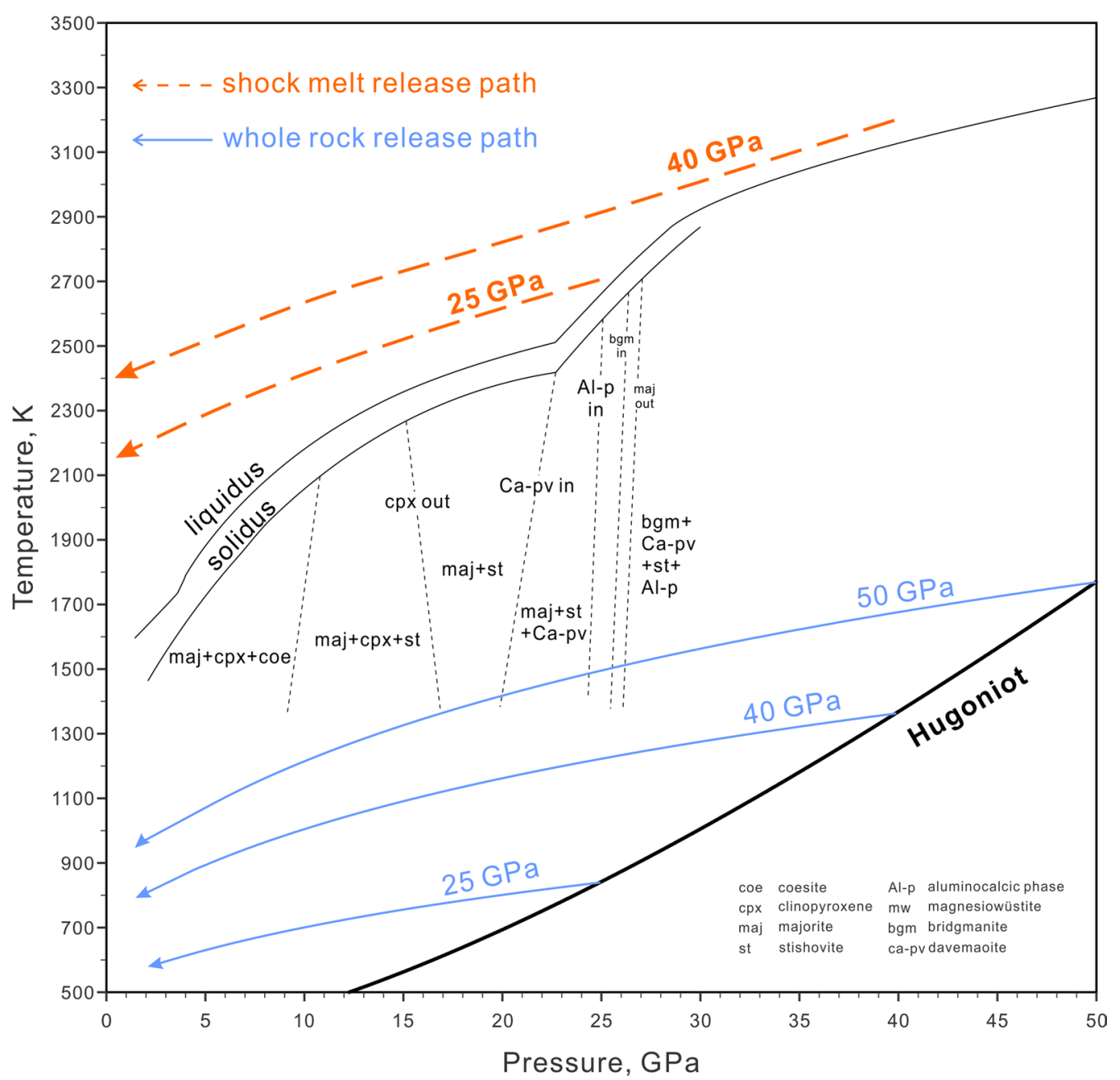

Fig. 6 The adiabatic release path of bulk basalt (light purple) and basaltic melt (orange) superimposed on a phase diagram based on MORB from Fei and Bertka (1999) and Hirose et al. (1999). The P-T Hugoniot is the same as Fig. 3. Parameters used for the calculations are listed in Table 1 and 2

Table 2 Parameters and temperatures of shock melt

\begin{tabular}{llll}
\hline $\boldsymbol{P}, \mathbf{G P a}$ & $\begin{array}{l}\text { Chondrite } \\
\mathbf{2 5 - 5 0}\end{array}$ & $\begin{array}{l}\text { Basalt } \\
\mathbf{2 5 - 4 0}\end{array}$ & Source \\
\hline$\gamma_{0}$ & 0.81 & 0.356 & 1 \\
$q$ & -1.41 & -1.63 & 1 \\
$\rho, \mathrm{g} / \mathrm{cm}^{3}$ & $3.7-4.1$ & $3.9-4.2$ & 2,3 \\
$\rho_{\mathrm{O},} \mathrm{g} / \mathrm{cm}^{3}$ & 2.8 & 2.5 & 2,3 \\
$T_{\text {shock, }}, \mathrm{K}$ & $2400-3300$ & $2700-3200$ & \\
$T_{\text {ps, }}, \mathrm{K}$ & $1815-2143$ & $2140-2394$ & \\
\hline
\end{tabular}

$\gamma_{0}$ and $q:$ zero-pressure Grüneisen parameter and the exponent factor. $\rho$ and $\rho_{\rho}$ : density at high and zero pressure. The shock temperature $T_{\text {shock }}$ of melt is assumed to be slightly above the liquidus. Post-shock temperature $T_{\mathrm{ps}}$ is calculated using the listed parameters

${ }^{1}$ Asimow (2012); ${ }^{2}$ Asimow (2015); ${ }^{3}$ Bajgain et al. (2015) pulse durations of tens of milliseconds. Nevertheless, the martian basalt NWA 8159 has a constant crystallization assemblage in a relatively thick melt vein that suggests a 100 ms shock pulse (Sharp et al. 2019) and a somewhat larger source crater.

The large temperature difference between the super liquidus shock melt and relatively cool host rock drives the rapid high-pressure quench of the shock melt by heat conduction. The heat flux is proportional to temperature gradient, based on Fourier's law. The heat transfer is also enhanced by turbulence of the shock melt that can transport hotter material to the interface with the colder bulk host (Adcock et al. 2017). The shock melt starts with a super liquidus temperature at $\sim 2400 \mathrm{~K}$ (red dot in Fig. 7). The bulk shock-temperature of the host rock is only 500-700 K (cyan path) at 20-25 GPa, corresponding to 


\section{shock stage classification}

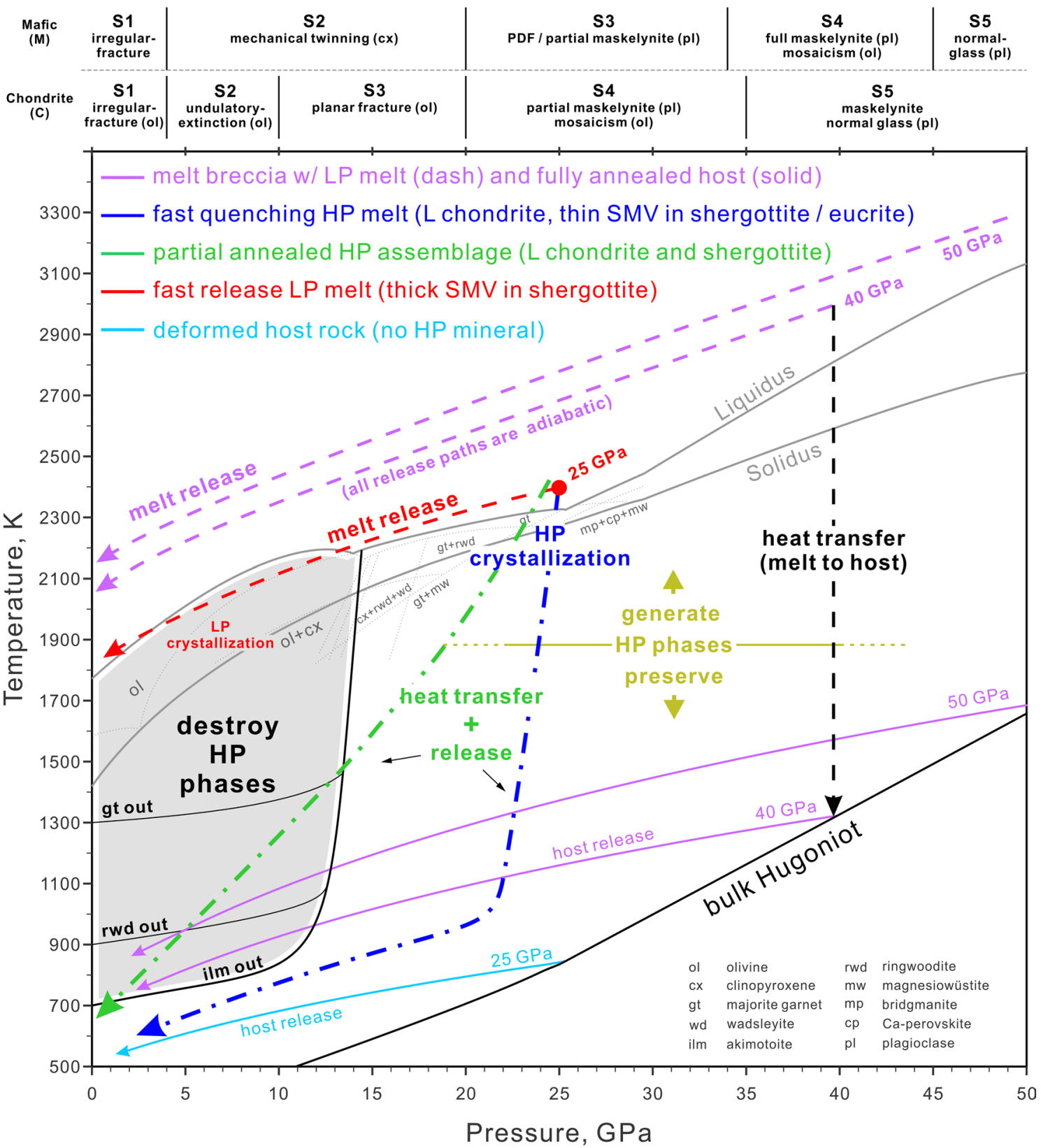

Fig. 7 The cooling paths of typical moderately to highly shocked meteorites. The adiabatic release paths (cyan, red and purple lines) are from Fig. 5. HP and LP melt refer to shock melt that crystallizes before and after pressure release, respectively. The vertical line represents pure heat transfer from shock melt veins (SMV) to solid groundmass without synchronous pressure drop by decompression. The dark yellow line shows the approximated temperature of triggering rapid HP transformation. The grey area represents the conditions for destruction of akimotoite (ilm), ringwoodite (rwd) and garnet ( $\mathrm{gt}$ ) by amorphization or back transformation. The blue and green lines represent combinations of decompression and synchronous heat-transfer, where blue corresponds to rapid thermal quench with crystallization at high pressure and green corresponds to a greater contribution for decompression, resulting in crystallization at slightly lower pressure and partial annealing in the grey area. The shown $P-T$ paths are technically for chondritic/ultramafic rocks but the concepts also work for mafic rocks. The top $x$-axis shows shock stage classification with deformation features of chondrite (C) and mafic meteorite (M) such as basaltic shergottite (Stöffler et al. 1991, 2018) 
a temperature difference of up to $1900 \mathrm{~K}$. This large temperature gradient between the shock melt and the surrounding host rock results in the rapid transfer of heat into the surrounding host rock (blue $P-T$ path in Fig. 7) and rapid thermal quench of the shock melt (Langenhorst and Poirier 2000; Xie et al. 2006b). If the shock pulse is longer than the time required to quench the melt, the melt will crystallize a high-pressure assemblage (Sharp and De Carli 2006). If such a long shock pulse occurs for samples within the isobaric shock zone, there would be no significant decompression during thermal quench and the resulting isobaric crystallization (blue path) would result in a constant crystallization assemblage throughout the quenched melt. This is apparently the scenario for many highly shocked $L$ chondrites that have constant or nearly constant crystallization assemblages, implying that the $P-T-t$ path and crystallization was dominated by thermal quench at high pressure and nearly isobaric (e.g. Chen et al. 1996; Ohtani et al. 2004; Sharp et al. 2015).

Second, the chondrite fragments entrained in the shock melt are heated rapidly to enable reconstructive transformation to HP polymorphs during the shock pulse (Fig. 8a). Although the duration of the shock pulse varies depending on the size of the impacting body and the location of the sample relative to the impact, the pulse duration is thought to be on the order of $1 \mathrm{~s}$ for highly shocked L chondrites (Chen et al. 2004; Ohtani et al. 2004; Beck et al. 2005; Sharp et al. 2015). Transformation of olivine on such a time scale requires a temperature in excess of $1600 \mathrm{~K}$ (Xie and Sharp 2007), illustrated by the dark yellow line and upward arrow in Fig. 7. The transformation of enstatite clasts to majorite, akimotoite or bridgmanite requires even higher temperatures because of the slow kinetics of enstatite transformations (Hogrefe et al. 1994; Lockridge 2015). The upward dark yellow arrow in Fig. 7 illustrates the rapid heating of an entrained mineral fragment to near solidus temperatures. Only material within the shock melt or immediately adjacent to the melt reach sufficiently high temperatures for reconstructive transformation during the shock pulse (Fig. 8a-c). The much rarer displacive transformation, such as zircon to reidite, can occur without extensive melting although higher local temperature would still greatly enhance the reaction (Leroux et al. 1999; Xing et al. 2020).

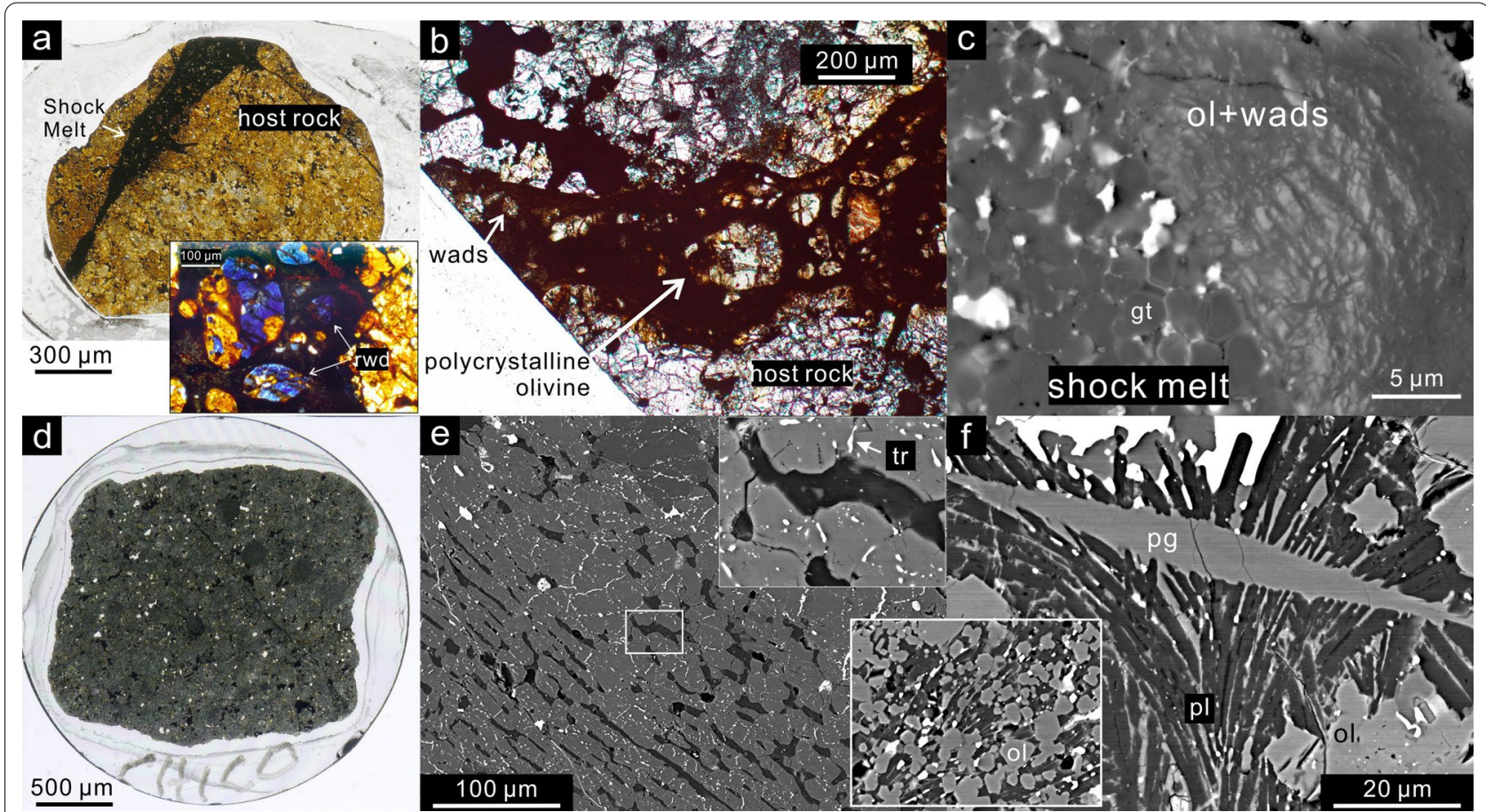

Fig. 8 Variable shock features in L chondrites previously classified as shock stage S5-6. a RC 106 (L6) thin section with a thick shock melt vein. The insert is a plane-polarized light (PPL) micrograph of the shock melt vein containing blue ringwoodite (rwd). $\mathbf{b}$ PPL micrograph of a shock melt vein in Mbale (L5-6). The clasts in the thin part of vein are wadsleyite (wads) aggregates and the thicker vein contains polycrystalline olivine. $\mathbf{c}$ backscattered electron (BSE) image of a polycrystalline olivine (ol) aggregate with trace wadsleyite in contact with majorite garnet (gt) in quenched Mbale shock melt. d Shock-darkened impact melt breccia Chico (L6). e BSE image of a barred olivine chondrule in melt breccia NWA 091 (L6). The troilite (tr) veinlets are disseminated in the olivine. f BSE image of recrystallized sodic pigeonite (pg)-plagioclase (pl)-olivine (ol) aggregate in Chico. The insert is another recrystallized olivine-plagioclase aggregate. Figures modified after Sharp et al. (2015), Hu (2016) and Hu and Sharp (2017) 
Thermal history is the key difference between HP mineral regions (previously S6) and the bulk host rock. Observable transformation of olivine or pyroxene cannot occur in the host-rock away from the shock melt because the bulk-shock temperature is only $600-800 \mathrm{~K}$ at $25 \mathrm{GPa}$ (cyan path in Fig. 7). The relatively low temperature of the host rock limits the shock metamorphic effects to mosaicism (S4-S5), planar deformation features (S4S5) and maskelynite (S5) outside the shock melt (Stöffler et al. 1991). In the recently revised scheme (Stöffler et al. 2018), these shock features are re-classified as S3-S5 (Fig. 7). This is consistent with shock classification of 2280 samples by Bischoff et al. (2019), who found that $70 \%$ of their 53 chondrite samples that contain ringwoodite are classified as shock stage up to S4 in regions distant from the shock melt. Stöffler et al. (1991) proposed that S6 shock features may result from local pressure-temperature excursions and therefore higher shock pressure than the bulk rock. Although significant pressure heterogeneities are expected during compression, pressure variations "ring down" to the equilibrium shock pressure in a very short time relative to the duration of the shock pulse and the formation of HP minerals (Sharp and De Carli 2006). Hydrocode simulations of mesoscale shock effects in chondrites confirm that local pressure excursions occur around high-impedance components (Moreau et al. 2017, 2018) and that shock pressures equilibrate in 10-20 ns. Although local temperature excursions are required to generate S6 features, the HP minerals form after the pressure heterogeneities have equilibrated.

Third, the HP minerals must cool below a critical temperature before pressure release in order to survive. At ambient pressure, ringwoodite and wadsleyite break down at temperatures above $900 \mathrm{~K}$ and back-transform to olivine within seconds at $T>1200 \mathrm{~K}$ ( $\mathrm{Hu}$ and Sharp 2017). The critical temperature for retrograde back transformation depends on the stability of the mineral and the kinetics of its back-transformation reaction. The critical temperature for garnet is $\sim 1300 \mathrm{~K}$, which makes garnet more resistant to back transformation than the olivine polymorphs (Thiéblot et al. 1998), and therefore a robust indicator of high pressure in partially annealed samples. Pyroxene's other two polymorphs, akimotoite and bridgmanite, break down at significantly lower temperatures of 700 and $400 \mathrm{~K}$, respectively (Ashida et al. 1988; Durben and Wolf, 1992) and bridgmanite is generally transformed to glass during or after decompression (Sharp et al, 1997). The grey area in Fig. 7 represents a critical pressure-temperature region of annealing for akimotoite through garnet. In highly shocked samples that retain HP minerals, heat transfer from the melt zones to the relatively cool host rock is the major mechanism for quenching shock melt and for cooling HP minerals sufficiently to survive under reduced pressure conditions.
Therefore, the $P-T-t$ paths for quench of HP minerals must be steep (high $\mathrm{d} T / \mathrm{d} P$ ) in order to cool below the $P-T$ conditions of back transformation (blue path in Fig. 7).

\subsection{Partially annealed samples}

The back-transformation of HP minerals in some classic S6 samples implies shallow $P-T$ paths (lower $\mathrm{d} T / \mathrm{d} P$ ) and insufficient cooling during pressure release. For example, EETA 79001 (shergottite) and Mbale (L chondrite) are highly shocked samples that contain fine-grained olivine aggregates, with remnants of ringwoodite or wadsleyite that are surrounded by radiating fractures from post-shock volume expansion (Walton 2013; Hu and Sharp 2017). These textures provide evidence of backtransformation of ringwoodite and wadsleyite and provide a mechanism for the origin of polycrystalline olivine aggregates. Remnants of high-pressure phases in the shock melt indicate that melt started at high pressure, but followed shallower $P-T$ paths (green path in Fig. 7 ) that crossed through conditions of ringwoodite back transformation. The clasts in the shock melt were heated to temperatures sufficiently high to enable rapid transformation of olivine to its HP polymorphs (Fig. 8b, c) but did not cool below the critical temperature for back transformation before low-pressure conditions were reached. In these cases, rapid decompression occurred while heat was being transferred from the shock melt to the surrounding host rock. In Mbale (L5-6), thinner shock veins contain wadsleyite while thick veins contain back transformed olivine (Fig. $8 \mathrm{~b}$ and c), indicating that the slowercooling thick vein had a shallower $P-T$ path than the thinner vein (Hu and Sharp 2017).

The $P-T-t$ path followed by any particular part of the sample will depend on the abundance of shock melt and the duration of the shock pulse. Graphically, the corresponding $P-T$ paths (blue and green paths in Fig. 7) will have variable $\mathrm{d} T / \mathrm{d} P$ slopes, depending on the amount of shock melt that is cooling during the shock pulse and release. For example a small melt vein or a melt vein edge would cool quickly by conduction and turbulence to the cooler host rock and would follow a relatively steep $P-T$ path (high pressure portion of blue and green lines in Fig. 7). Similarly, a larger volume of melt contains higher internal energy that takes longer to dissipate and would therefore follow a relatively shallow $P-T$ path (green line in Fig. 7) that may traverse the back-transformation regime of low- $P$ and high- $T$ (grey region). If the sample quenched in the isobaric shock zone, the paths would start with steep isobaric cooling, followed by shallowing of the $P-T-t$ path. The extent of the isobaric cooling trend is inversely related to the amount of melt being cooled by conduction, such that the smallest volume of melt would produce a most stable isobaric segment for 
quenching before decompression. This is the case for many shocked $\mathrm{L}$ chondrites. In samples experiencing a short isobaric shock pulse, the $P-T-t$ would start with a steep slope and quickly turn to a shallower slope (blue and green lines in Fig. 7). Outside of the isobaric zone, all $P-T-t$ paths would be non-vertical decompression paths with the slope determined by the competing effects of decompression and thermal conduction to the cooler host rock. In shergottites, such as EETA 79,001, the shock pulse is inferred to be short and anisobaric, resulting in a $P-T$ path through the back-transformation regime (Walton 2013). The back-transformed Mbale L chondrite, which crystallized a relatively small volume of melt at $14-18 \mathrm{GPa}$, is unlikely to have a lengthened cooling time caused by a high bulk-shock temperature ( $\mathrm{Hu}$ and Sharp 2017). We therefore infer that Mbale experienced a shorter shock pulse than most HP-mineral bearing L chondrites (Hu and Sharp 2017). Furthermore, more pervasive melting and higher shock and post-shock temperature, as in impact melt breccias, would lead to more extensive back transformation and post-shock annealing.

Larger shock-melt volumes produce shallow $P-T-t$ paths that are dominated by decompression. The red line in Fig. 7 illustrates the adiabatic cooling path for a shock melt at $25 \mathrm{GPa}$ that decompresses without dissipation of heat to the host rock. This is not the case for HP-mineralbearing "S6" L chondrites, which have small amounts of shock melt and steep $P-T-t$ paths dominated by heat transfer. However, for small high-velocity impacts on planets, the shock pulse could be much shorter, resulting in decompression dominating the $P-T-t$ quench path (Beck et al. 2005). Several shergottites have melt crystallization assemblages with olivine and pyroxene or glass coexisting with HP products of olivine transformation at 25 GPa (Miyahara et al. 2011b, 2016; Walton 2013; Walton et al. 2014). In Tissint (olivine-phyric shergottite) for instance, only the micron thin veins crystallize and preserve stishovite and ringwoodite whereas the $\mathrm{mm}$ thick veins consist of olivine and clinopyroxene (Walton et al. 2014). The low-pressure assemblage of their quenched shock melts indicates that the corresponding $P-T-t$ paths of the melt are closer to the adiabatic release path of melt (red line in Fig. 7).

\subsection{Impact melt breccias}

Impact melt breccias have abundant shock features and evidence of high temperature, but they lack direct evidence of high pressure phase transitions. Sample such as NWA 091 and Chico (Bogard et al. 1995; Yolcubal et al. 1997; Hu 2016), have shock features that include recrystallization of olivine, blackening of silicates by disseminated metal-sulfide, feldspathic normal glass and pervasive impact melt (Fig. $8 \mathrm{~d}-\mathrm{f}$ ). These samples were classified as highly shocked S6 samples by Stöffler et al. (1991), although they lack typical S6 shock veins and HP minerals. Bischoff et al (2019) classified Chico as an L6 breccia that contains fragments of melt breccia and we have studied a portion of melt breccia. Unlike a hand sample with pressure equilibrium in nanoseconds, the $105 \mathrm{~kg}$ Chico can have portions experiencing different levels of shock. The direct evidence for strong shock in these samples includes common recrystallization of rock-forming minerals and disseminated troilite that indicates mobile sulfide melt throughout the sample $\mathrm{Hu}$ 2016). The troilite in these samples occurs as strings of tiny inclusions in olivine and pyroxene rather than veins (Fig. 8e). We interpret this texture to indicate that the silicate minerals were fractured during shock and the fractures were filled by sulfide melt. During subsequent annealing, the fractures healed, leaving strings of sulfide inclusions where fractures had been (Rubin 1992).

The severity of shock recorded in impact melt breccias is not well defined, but pervasive melting implies significantly higher shock pressures than those of S6-bearing chondrites. Moreau et al. $(2017,2018)$ used mesoscale hydrocode simulations to investigate the shock behavior of olivine-troilite-iron mixtures that resembles ordinary chondrites. The simulations at bulk shock pressures of 40-50 GPa result in considerable post-shock melting of troilite and the onset of local olivine melting. Moreau et al. (2017) inferred that $>35 \mathrm{GPa}$ is the shock pressure range for pervasive silicate blackening. This is consistent with our interpretation that extensive darkening requires higher pressures than those of HP-mineral bearing "S6" samples $(<30 \mathrm{GPa})$. In blackened chondrite samples such as Chico, the sulfide particles and veinlets are much finer-grained than the common crack-filling sulfide in other chondrites and the sulfide particles occur in strings without co-existing fractures. We suggest that some chondrite melt breccias, including Chico and NWA 091, underwent high degrees of recrystallization and annealing at high post-shock temperatures ( $\mathrm{Hu} 2016)$.

Shock pressures of 40-50 GPa would result in abundant shock melt, shallow $P-T-t$ paths and post-shock temperatures too high for preservation of HP minerals (Fig. 7). Chico contains polycrystalline olivine-pyroxeneplagioclase aggregates (Fig. 8e, f) that appear to result from a combination of back-transformation, recrystallization and low-pressure melt crystallization (solid and dashed purple lines in Fig. 7). During a shock pulse to 40-50 GPa, the olivine single crystals in the shock melt would transform to polycrystalline aggregates of wadsleyite, ringwoodite or bridgmanite plus oxide (Ito and Takahashi 1989). During pressure release from 40 to $50 \mathrm{GPa}$, these HP minerals would follow a shallow $P-T$ path between that of melt and the bulk rock (purple lines in 
Fig. 7). Based on observations in partially annealed samples, this would result in post-shock temperatures high enough to back-transform ringwoodite to olivine and cause recrystallization of back-transformed aggregates (Fig. 8f). Shock pressure greater than $\sim 50 \mathrm{GPa}$ would result in large melt fractions, generally shallower $P-T$ decompression paths (Hu and Sharp 2017), and postshock annealing out of high-shock indicators (grey area in Fig. 7). It is worth noting that, although the melt breccia may still contain thin shock veins that experienced relatively fast cooling with steeper $P-T$ curves, the bulk post-shock temperature of the sample sits in the backtransformation regime and destroys the HP minerals.

Shock to $50 \mathrm{GPa}$ results in a bulk release $P-T-t$ path and a post shock temperature that is too hot for the preservation of most HP minerals. The bulk release path of $50 \mathrm{GPa}$ (solid purple line in Fig. 7), which ends in the grey back-transformation area in Fig. 7, represents the lowest thermal history possible during and right after shock in such a sample. This illustrates that even the coldest parts of such a sample would experience back transformation of HP minerals and recrystallization of low-pressure mineral aggregates (Fig. 8e and f). The release paths for pure melt (dashed purple lines in Fig. 7) are above the liquidus and would result in crystallization at low pressure after pressure release. In natural melt-breccia samples, the release paths would be between these two end-members, with shock melt following a very shallow $P-T$ path close to the liquidus. In this scenario, shock-melt crystallization may occur at elevated pressures, but at pressures generally too low to produce typical HP minerals and any HP minerals formed by transformation would not survive the high post-shock temperatures.

\section{Shock pressure estimation by $P-T-t$ paths}

Realistic $P-T-t$ paths of shock metamorphism in chondrites are important for the interpretation of heterogeneous shock effects and conditions that are well off the bulk Hugoniot, particularly for the temperatures. The formation of shock melt veins results in local regions that are far hotter than that predicted by the bulk-rock Hugoniot for a given shock pressure. Formation of these local melt zones likely involves transient local pressure excursions, as described by Stöffler et al. (1991) but these transient pressure variations ring down to the equilibrated shock pressure at least $10^{6}$ times faster than the crystallization of even micron-sized shock melt (Langenhorst and Poirier 2000). More importantly, these local excursions, caused by pore collapse and shear during compression, result in temperature heterogeneities that are far above the temperature of the bulk-rock Hugoniot (Sharp and DeCarli 2006; Moreau et al. 2018). These temperature heterogeneities not only produce local melting and
HP minerals; they also enhance thermally activated deformational processes. For example, the pressure for solid-state amorphization of plagioclase is strongly temperature dependent (Daniel et al. 1997; Tomioka et al. 2010; Kubo et al. 2010; Sharp et al. 2019) and the pressure at which PDFs and mosaicism occur decreases with increasing temperature (Huffman et al. 1993; Bauer 1979; Bowden 2002). Moreover, ignoring temperature heterogeneities would lead to difficulties explaining the significant discrepancy between co-existing shock features in many samples, such as sharp extinction of plagioclase in S4-S6 chondrites (Hu and Sharp 2017; Fritz et al. 2017). The thermal dependence of shock metamorphic effects explains why they are strongest (S6) in and adjacent to shock veins, but decrease to S5 and S4 with increasing distance from shock veins in some samples (Bischoff et al. 2019).

Given that some parts of a shocked sample deviate from the bulk Hugoniot conditions and are therefore "non-equilibrium" shock features (Stöffler et al.1991), they are still useful for estimating shock pressure because they are hot enough to drive thermally activated mineral reactions. For a typical HP-mineral bearing sample, the shock pressure needs to be roughly in the range as the stability field of the observed HP minerals, i.e. 15-30 GPa. In principle, HP minerals can form metastably at lower pressure than equilibrium under high strain (Melosh 1989) or by a metastable reaction (Walton et al. 2014; Kubo et al. 2015). The shock melt must experience sufficiently high pressure to crystallize HP minerals and contain enough heat to transform entrained clasts to HP phases. In the 15-30 GPa pressure range, the bulk shock temperature (Hugoniot temperature) is low enough for the bulk sample to act as a very large heat sink that drives rapid quench of the shock melt before and during decompression. These local "non-equilibrium" S6 shock features are essential for creating and preserving mineralogical evidence of high pressure.

If shock pressure were significantly higher than the 15-30 GPa indicated by HP mineral stability, the mineralogical evidence would not be well preserved (Fig. 7). For a shock pressure between 25 and $35 \mathrm{GPa}$, we would expect bridgmanite and magnesiowüstite to be the dominant HP minerals to crystallize from the shock melt and to form from the transformation of entrained mineral fragments. However, bridgmanite has the lowest preservation temperature of all of the HP minerals and readily decomposes at ambient pressure and temperatures in excess of $\sim 400 \mathrm{~K}$ (Durben and Wolf 1992). This preservation temperature is lower than the post-shock release temperatures from $25 \mathrm{GPa}$ (Fig. 6). Although bridgmanite can form in shocked meteorites, the shock conditions where bridgmanite should dominate the mineralogy 
cannot preserve bridgmanite after pressure release. This explains why crystalline bridgmanite is so rare in shocked chondrites, having only been found as a trace component in Tenham (L6; Tomioka and Fujino 1997; Tschauner et al. 2014). Instead, glassy grains with bridgmanite stoichiometry have been reported to coexist with akimotoite and ringwoodite in the quenched shock melt of Acfer 040 and Tenham (L6; Sharp et al. 1997; Xie et al. 2006b). The texture, composition and amorphous state provide strong evidence that these glassy grains were bridgmanite that crystallized from the shock melt and decomposed upon pressure release. Also, evidence for the transformation of olivine to bridgmanite (now pyroxene glass) plus magnesiowüstite has been reported from Martian meteorites, including Tissint (Walton et al, 2014; Miyahara et al. 2016; Ma et al. 2016) and Dar al Gani 735 (Miyahara et al. 2011b). If highly shocked meteorites were shocked to pressures above $25 \mathrm{GPa}$, we would expect to find abundant evidence for amorphous or transformed bridgmanite in S6 samples. The rarity of this evidence suggests that most shocked meteorites with S6 shock effects did not experience equilibrated shock pressures in excess of about $25 \mathrm{GPa}$. For a shock pressure of 40-50 GPa, even the bulk release temperature would be high enough to destroy all HP minerals (solid purple line in Fig. 7). In samples shocked to these pressures, the primary evidence for shock metamorphism would be extensive melting, darkening and recrystallization, as in the impact melt breccias.

\subsection{S6 shock-pressure inconsistencies and the use of HP minerals for evaluating shock stage classification}

Shock deformation features in the unmelted portion of the meteorites have been the gold standard for shock classification and pressure estimation since Stöffler et al (1991) published their shock classification. Shock recovery experiments are an important technique for calibrating the corresponding shock pressures of these deformational features (e.g. Milton and DeCarli 1963; Stöffler 1972; Kieffer et al. 1976; Bauer 1979; Jeanloz 1980; Ostertag 1983; Stöffler and Langenhorst 1994) and they provide the basis for most of the Stöffler et al (1991) pressure calibration. However, S6 features, particularly HP minerals, are not well calibrated by shock recovery experiments. $\mathbf{S 6}$ shock effects, which are closely associated with shock melting, are interpreted by Stöffler et al (1991) to represent shock pressures from 50 to $90 \mathrm{GPa}$, with ringwoodite requiring 80-90 GPa to form. However, pinning of the pressure scale to 80-90 GPa for ringwoodite is not based on the formation of ringwoodite in shock recovery experiments, but rather on the lack of such shock synthesis. Without well calibrated pressures for S6 shock effects, this interpretation of S6 shock conditions, based on high-pressure minerals, is not well supported.

Chen et al. (1996) used TEM to characterize garnetbearing melt-vein assemblages in Sixiangkou (L6) and the entrained ringwoodite and majorite that formed from olivine and enstatite. In that paper, the majorite-pyrope garnet plus magnesiowüstite assemblage was interpreted to represent melt-vein crystallization at 20-24 GPa and between 2050 and $2300{ }^{\circ} \mathrm{C}$. This shock-pressure estimate was far lower than the 80-90 GPa estimate of ringwoodite formation of Stöffler et al. (1991) and started a heated discussion over the meaning of S6 shock effects and the use of HP mineral stability to constrain shock pressure. Here we use our modeling of shock temperatures and discussions of $P-T-t$ cooling paths to provide insight into the importance of HP minerals and the S6 classification of shocked meteorites.

The central issue in the discussion of S6 features is the interpretation of shock-melt crystallization pressure versus the equilibrium shock pressure. Stöffler et al. (1991) state that S6 features represent local pressure-temperature excursions, within and near shock melt, but they are less clear about how to interpret those excursions in the context of equilibrium shock pressure. S6 features, especially blue ringwoodite aggregates in shock veins, have become an easily observed indicator of S6 shock stage. More recently, Stöffler et al. (2018) stated that HP minerals in shocked meteorites are duration-dependent and represent an extended pressure release regime that should be ignored in the interpretation of equilibrium shock pressures and they removed the use of HP minerals from $\mathrm{S} 6$ criteria and from most of the revised classification schemes. In particular, HP minerals are excluded from ultramafic and mafic samples (e.g. shergottites, eucrites etc.) and only mentioned as a minor possibility for S5-6 in chondrites (>35 GPa), in contrast to an exclusively S6-defining feature in Stöffler et al. (1991). Although HP minerals do not support the pressure calibration of S6 in Stöffler et al (1991) or S5-6 in Stöffler et al. (2018), they do provide valuable constraints on shock pressure. The durations of non-equilibrium pressure excursions are on the order of $10-20 \mathrm{~ns}$, which is too short for significant HP-mineral crystallization or transformation at extreme pressure. Instead, the high temperatures generated are much more important in creating HP-mineral signatures because they persist long after pressure equilibration. These high temperature zones, which are far off the bulk Hugoniot, are nearly the only parts of the samples hot-enough to record a mineralogical signature of shock pressure.

Because shock deformation features, such as fracturing and mosaicism, can occur in a wide range of shock pressures (e.g. Bauer 1979), HP mineral assemblages provide 
complementary constraints on shock pressure, temperature and duration that should not be ignored. The timing of shock-melt crystallization relative to pressure release is critical for interpreting pressure constraints from HP minerals. Many highly shocked L6 chondrites have nearly constant shock-vein crystallization assemblages that suggest a narrow range of crystallization pressure (e.g. <15-25 GPa; Chen et al. 1996; Sharp and DeCarli 2006; Chen and Xie 2008; Miyahara et al. 2011a; Hu and Sharp 2017). This implies that the shock-veins in most highly shocked L chondrites represent crystallization at equilibrium shock pressures between 15 and 25 GPa. Crystallization during decompression cannot reconcile the difference between very high pressures for S6 features of Stöffler et al. $(1991,2018)$ and the 15-25 GPa crystallization pressures recorded in $\mathrm{L}$ chondrites. The $P-T-t$ paths for S6 shock veins are driven by a combination of decompression and heat transfer to the surrounding bulk rock (blue and green lines in Fig. 7). It is highly unlikely that shock-melts formed at pressures in excess of $50 \mathrm{GPa}$ and temperatures over $3000 \mathrm{~K}$ would all follow $P-T-t$ paths that consistently cross the liquidus between 15 and $25 \mathrm{GPa}$ regardless of the size and cooling rate of the melt zone. Such a large drop in crystallization pressures would result in a large range of crystallization assemblages in a given sample and between samples. Moreover, a quench path from $50 \mathrm{GPa}$ that crosses the liquidus at 15-25 GPa would result in $P-T-t$ conditions and post-shock temperatures that would destroy all HP minerals (solid purple lines in Fig. 7). The narrow pressure ranges recorded in many S6 L chondrites are consistent with shock in the isobaric zone (Fritz et al. 2017) of the large impact that broke up the L-chondrite parent body.

A similar scenario of HP minerals associated with shock melt occurs in the ultramafic-mafic achondrites, such as shergottites and eucrites, but these meteorites do not all record a narrow range of crystallization pressures. Martian meteorites commonly contain both high- and low-pressure features that represent crystallization and quenching through a range of release paths and shock outside of the isobaric zone (Walton et al. 2014; Fritz et al. 2017). This complication does not jeopardize the shock-pressure estimation from HP minerals but rather provides more information for constructing possible $P$ $T-t$ paths for various parts of a given sample (green and red paths in Fig. 7). A HP mineral assemblage in the shergottite Zagami was first reported by Langenhorst and Poirier (2000) and majorite plus ringwoodite/wadsleyite assemblages, similar to those in shocked chondrites, were first reported in SNCs by Malavergne et al. (2001). Since then, many HP minerals have been recognized in mafic/ ultramafic achondrites, indicating shock pressures of 15-30 GPa (Tomioka and Miyahara 2017 and references therein). Even the post-stishovite silica polymorph seifertite (Sharp et al. 1997; El Goresy et al. 2008; Miyahara et al. 2013), which has a stability field of $>100 \mathrm{GPa}$ (Grocholski et al. 2013), can form metastably from cristobalite within the 15-30 GPa pressure range (Kubo et al. 2015). This pressure range is in good agreement with the moderate deformational features, such as partial to full diaplectic glasses and weak mosaicism in mafic minerals, found in Martian meteorites and eucrites (e.g. Langenhorst and Poirier 2000; Pang et al. 2016; Sharp et al. 2019). As mentioned above, shocked achondrites generally record shorter HP pulses, which makes the back-transformation and decompression sequence clearer in these samples (e.g. Walton 2013; Sharp et al. 2019; Hu et al. 2020). These occurrences are inconsistent with HP minerals originating from local/transient pressure excursions (Fritz and Greshake 2009). The samples truly shocked to $\sim 40 \mathrm{GPa}$ and above, would have high bulk temperature, pervasive melting and no HP minerals (e.g. ALHA 77,005; Walton and Herd 2007), similar to chondritic melt breccias. The claim that all the meteoritical HP minerals formed during pressure release from extreme pressures is not supported by observed assemblages. Therefore HP minerals can and should be used as shock stage indicator of moderate pressure in ultramafic-mafic achondrites.

The reconciliation of S6 conditions in shocked meteorites comes from the heterogeneous nature of shock effects and shock stage in these samples. Bischoff et al. (2019) reported shock classification results from 2280 shocked ordinary chondrites and specifically addressed the issue of shock-stage heterogeneity and S6 classification. They found that among $52 \mathrm{~L}$ chondrites and one LL chondrite with ringwoodite, 23 had more crystalline than amorphous plagioclase and an additional 16 had more than $25 \%$ crystalline plagioclase. This indicates that more than $70 \%$ of the ringwoodite-bearing chondrites belong to the shock stage S4 (Bischoff et al, 2019). They also stress the importance of sampling when classifying heterogeneous samples and the need to look at more than one small thin section in classifying shock stage. For example, Tenham, the iconic S6 chondrite which retains crystalline bridgmanite (Tschauner et al. 2014), has melt-vein free material that is classified as S4 (Bischoff et al. 2019). These results indicate that the S6 classification based on HP minerals is not a valid part of a progressive series of shock effects, but rather the result of local hot zones in samples shocked to predominantly S4 conditions. The 15-30 GPa (majorite predominant) shock pressures inferred from the crystallization of shock melt in previous $\mathrm{S} 6$ samples is well within the range of S4 conditions originally proposed by Stöffler et al. (1991). The presence of HP minerals, including the easily recognized presence of ringwoodite transformed 
from olivine, are not an indication of very high shock pressures, but rather an indication of moderate S4 shock pressures. Therefore, HP minerals in shock veins should not be ignored in shock classification because they provide evidence of moderate shock pressure and constraints on the $P-T-t$ history of the shock melt through quench and decompression.

\section{Conclusions}

High-pressure minerals are important signatures of shock in meteorites, but they are not necessarily an indication of very high shock pressures. Their production and preservation requires complex but wellconstrained $P-T-t$ paths from very high temperatures during shock to low temperature after pressure release. Calculations of shock and release temperatures provide the context for constraining these complex $P-T-t$ paths. Observed high-pressure minerals in shocked meteorites correspond to shock pressures of 15-30 GPa. The corresponding HP liquidus for chondrites is approximately $2300 \mathrm{~K}$, which is hot enough to enable the transformation of low-pressure minerals, in association with shock melt, to their high-pressure polymorphs. At these pressures, the bulk shock temperature is low enough for the host sample to act as a heat sink to rapidly cool shockmelt veins and pockets, resulting in rapid quench (high $\mathrm{d} T / \mathrm{d} P)$ of these hot zones before and during decompression. The bulk meteorite is also sufficiently cool so that only deformational shock features occur outside the melt veins. In contrast, if a meteorite sample experiences even slightly hotter background temperature and/ or shorter shock pulse, the quench of shock melt during decompression would have a gentle $\mathrm{d} T / \mathrm{d} P$ slope which can leave the newly-formed HP assemblage too hot to survive at reduced pressure. The shock veins in samples with abundant melt, such as melt breccias, generally crystallize low-pressure assemblages and anneal out many shock deformation effects. At 40-50 GPa, the bulk shock temperature is too high for HP minerals to cool sufficiently to survive at low pressure. Samples shocked to such high pressures will only retain high-temperature features, such as extensive melting, darkening and recrystallization. The presence of ringwoodite in many chondritic samples, which was commonly considered as evidence of shock stage 56 , is not an indication of veryhigh shock pressure, but rather an indication of moderate shock pressures consistent with shock stage S4.

\section{Abbreviations}

HP: High pressure; SMV: Shock melt vein; PDF: Planar deformation features; MORB: Mid-ocean ridge basalt; SNC: Shergottites, nakhlites, chassignites.

\section{Acknowledgements}

We thank Dr. Naotaka Tomioka and an anonymous reviewer for their careful review and constructive comments. We also thank Dr. Erin Walton and an anonymous reviewer for reviewing an earlier version of this manuscript. We acknowledge the late Prof. Ahmed El Goresy for his many contributions to the study of HP minerals in shocked meteorites. We miss and gratefully thank the late Paul DeCarli who shared his wealth of knowledge on shock and mineral physics with us since early 2000s. We thank Dr. Paul Asimow for the guidance on thermodynamic calculations.

\section{Authors' contributions}

TGS conceived the initial concepts of this study. JH and TGS designed this study. JH performed the thermodynamic calculations. JH and TGS wrote the manuscript. All authors read and approved the final manuscript.

\section{Funding}

The study was initially funded by NASA Cosmochemistry Grant 12-COS120002. JH is supported by NASA Solar System Workings Grant 80NSSC18K0532 and NSF Award 1725349. TGS is supported by NASA Emerging Worlds Grant 17-EW17_2-0090.

\section{Availability of data and materials}

All data generated or analyzed during this study are included in this published article.

\section{Declarations}

\section{Competing interests}

The authors declare that they have no competing interests.

\section{Author details}

${ }^{1}$ Division of Geological and Planetary Sciences, California Institute of Technology, Pasadena, CA 91125, USA. ${ }^{2}$ School of Earth and Space Exploration, Arizona State University, Tempe, AZ 85287, USA.

Received: 28 August 2021 Accepted: 18 December 2021

Published online: 05 January 2022

\section{References}

Adcock CT, Tschauner O, Hausrath EM, Udry A, Luo SN, Cai Y, Ren M, Lanzirotti A, Newville M, Kunz M, Lin C (2017) Shock-transformation of whitlockite to merrillite and the implications for meteoritic phosphate. Nat Commun 8:14667

Agee CB, Li J, Shannon MC, Circone S (1995) Pressure-temperature phase diagram for the Allende meteorite. J Geophys Res Solid Earth 100(B9):17725-17740

Ahrens TJ, Gregson V Jr (1964) Shock compression of crustal rocks: data for quartz, calcite, and plagioclase rocks. J Geophys Res 69(22):4839-4874

Ahrens TJ, O'Keefe JD (1972) Shock melting and vaporization of lunar rocks and minerals. Moon 4:214-249

Anderson WW, Ahrens TJ (1998) Shock wave equations of state of chondritic meteorites. In: AIP conference proceedings, AIP Publishing pp 115-8

Anderson DL, Kanamori H (1968) Shock-wave equations of state for rocks and minerals. J Geophys Res 73(20):6477-6502

Asahara Y, Kubo T, Kondo T (2004) Phase relations of a carbonaceous chondrite at lower mantle conditions. Phys Earth Planet Inter 143-144:421-432

Ashida T, Kume S, Ito E, Navrotsky A (1988) $\mathrm{MgSiO}_{3}$ ilmenite: Heat capacity, thermal expansivity, and enthalpy of transformation. Phys Chem Miner 16(3):239-245

Asimow PD (2012) Shock compression of preheated silicate liquids: apparent universality of increasing Grüneisen parameter upon compression. AIP Conf Proc 1426(1):887-890

Asimow PD (2015) 2.16 - Dynamic compression. In: Schubert G (ed) Treatise geophys, 2nd edn. Elsevier, Oxford, pp 393-416

Asimow PD (2018) Chapter 15 - melts under extreme conditions from shock experiments. In: Kono Y, Sanloup C (eds) Magmas Press. Elsevier, Amsterdam, pp 387-418 
Bajgain S, Ghosh DB, Karki BB (2015) Structure and density of basaltic melts at mantle conditions from first-principles simulations. Nat Commun 6:8578

Bauer JF (1979) Experimental shock metamorphism of mono- and polycrystalline olivine-a comparative study. In: Proceedings of 10th lunar planet science conference, pp 2573-2596

Beck P, Gillet P, Gautron L, Daniel I, El Goresy A (2004) A new natural high-pressure $(\mathrm{Na}, \mathrm{Ca})$-hexaluminosilicate $\left[\left(\mathrm{Ca}_{x} \mathrm{Na}_{1-x}\right) \mathrm{Al}_{3+x} \mathrm{Si}_{3-x} \mathrm{O}_{11}\right]$ in shocked Martian meteorites. Earth Planet Sci Lett 219:1-12

Beck P, Gillet P, El Goresy A, Mostefaoui S (2005) Timescales of shock processes in chondritic and martian meteorites. Nature 435:1071-1074

Binns RA (1967) Stony meteorites bearing maskelynite. Nature 213(5081):1111-1112

Binns RA, Davis RJ, Reed SJB (1969) Ringwoodite, natural (Mg, Fe) ${ }_{2} \mathrm{SiO}_{4}$ spinel in the Tenham meteorite. Nature 221:943-944

Bischoff A, Schleiting M, Patzek M (2019) Shock stage distribution of 2280 ordinary chondrites-Can bulk chondrites with a shock stage of $\$ 6$ exist as individual rocks? Meteorit Planet Sci 54(10):2189-2202

Bogard DD, Garrison DH, Norman M, Scott ERD, Keil K (1995) ${ }^{40} \mathrm{Ar}-{ }^{39} \mathrm{Ar}$ age and petrology of Chico: large-scale impact melting on the $L$ chondrite parent body. Geochim Cosmochim Acta 59:1383-1399

Boslough MB (1984) Shock-wave properties and high-pressure equations of state of geophysically important materials. Dissertation, California Institute of Technology

Bowden KE (2002) Effects of loading path on the shock metamorphism of porous quartz: an experimental study. Ph.D. thesis.

Bowling TJ, Johnson BC, Wiggins SE, Walton EL, Melosh HJ, Sharp TG (2020) Dwell time at high pressure of meteorites during impact ejection from Mars. Icarus 343:113689

Chao ECT, Shoemaker EM, Madsen BM (1960) First natural occurrence of Coesite. Science 132(3421):220-222

Chao ECT, Fahey JJ, Littler J, Milton DJ (1962) Stishovite, $\mathrm{SiO}_{2}$, a very high pressure new mineral from Meteor Crater. Arizona J Geophys Res 67(1):419-421

Chen M, Xie X (2008) Two distinct assemblages of high-pressure liquidus phases in shock veins of the Sixiangkou meteorite. Meteorit Planet Sci 43:823-828

Chen M, Sharp TG, El Goresy A, Wopenka B, Xie X (1996) The majorite-pyrope + magnesiowüstite assemblage: constraints on the history of shock veins in chondrites. Science 271:1570-1573

Chen M, El Goresy A, Gillet P (2004) Ringwoodite lamellae in olivine: clues to olivine-ringwoodite phase transition mechanisms in shocked meteorites and subducting slabs. Proc Natl Acad Sci USA 101:15033-15037

Daniel I, Gillet P, McMillan PF, Wolf G, Verhelst MA (1997) High-pressure behavior of anorthite: compression and amorphization. J Geophys Res Solid Earth 102(B5):10313-10325

Dodd RT, Jarosewich E (1979) Incipient melting in and shock classification of L-group chondrites. Earth Planet Sci Lett 44(2):335-340

Durben DJ, Wolf GH (1992) High-temperature behavior of metastable $\mathrm{MgSiO}_{3}$ perovskite: a Raman spectroscopic study. Am Mineral 77(7-8):890-893

El Goresy A, Chao ECT (1976) Evidence of the impacting body of the Ries crater-the discovery of $\mathrm{Fe}-\mathrm{Cr}-\mathrm{Ni}$ veinlets below the crater bottom. Earth Planet Sci Lett 31(3):330-340

El Goresy A, Dubrovinsky L, Sharp TG, Chen M (2004) Stishovite and poststishovite polymorphs of silica in the shergotty meteorite: their nature, petrographic settings versus theoretical predictions and relevance to Earth's mantle. J Phys Chem Solids 65:1597-1608

El Goresy A, Dera P, Sharp TG, Prewitt CT, Chen M, Dubrovinsky L, Wopenka B, Boctor NZ, Hemley RJ (2008) Seifertite, a dense orthorhombic polymorph of silica from the Martian meteorites Shergotty and Zagami. Eur J Mineral 20(4):523-528

Fei Y, Bertka CM (1999) Phase transitions in the Earth's mantle and mantle mineralogy. In: Fei Y, Bertka CM, Mysen BO (eds) Mantle petrology: field observations and high pressure experimentation. Geochemical Society, New York, pp 189-207

Ferrière L, Brandstätter F (2015) What is Maskelynite? Back to the original description and thin sections in which it was first described. In: 78th annual meeting of the Meteoritical Society, Berkeley, California, USA, 27-31 July 2015, p 5184

Fredriksson K, DeCarli P, Aaramae A (1963) Shock-induced veins in chondrites. Space Res 3(196):3
Fritz J, Greshake A (2009) High-pressure phases in an ultramafic rock from Mars. Earth Planet Sci Lett 288:619-623

Fritz J, Greshake A, Fernandes VA (2017) Revising the shock classification of meteorites. Meteorit Planet Sci 52(6):1216-1232

Fukimoto K, Miyahara M, Sakai T, Ohfuji H, Tomioka N, Kodama Y, Ohtani E, Yamaguchi A (2020) Back-transformation mechanisms of ringwoodite and majorite in an ordinary chondrite. Meteorit Planet Sci 55(8):1749-1763

Gillet P, El Goresy A (2013) Shock events in the solar system: the message from minerals in terrestrial planets and asteroids. Annu Rev Earth Planet Sci 41:257-285

Goranson RW, Bancroft D, Burton BL, Blechar T, Houston EE, Gittings EF, Landeen SA (1955) Dynamic determination of the compressibility of metals. J Appl Phys 26(12):1472-1479

Grocholski B, Shim S-H, Prakapenka VB (2013) Stability, metastability, and elastic properties of a dense silica polymorph, seifertite. J Geophys Res Solid Earth 118(9):4745-4757

Herzberg C, Zhang J (1996) Melting experiments on anhydrous peridotite KLB1: compositions of magmas in the upper mantle and transition zone. J Geophys Res Solid Earth 101:8271-8295

Heymann D (1967) On the origin of hypersthene chondrites: Ages and shock effects of black chondrites. Icarus 6(1-3):189-221

Hirose K, Fei Y, Ma Y, Mao H-K (1999) The fate of subducted basaltic crust in the Earth's lower mantle. Nature 397(6714):53-56

Hogrefe A, Rubie DC, Sharp TG, Seifert F (1994) Metastability of enstatite in deep subducting lithosphere. Nature 372(6504):351-353

Hu J, Sharp TG (2017) Back-transformation of high-pressure minerals in shocked chondrites: low-pressure mineral evidence for strong shock. Geochim Cosmochim Acta 215:277-294

$\mathrm{HuJ}$ (2016) Shock Metamorphism in ordinary chondrites: constraining pressure and temperature history. Dissertation, Arizona State University

Hu S, Li Y, Gu L, Tang X, Zhang T, Yamaguchi A, Lin Y, Changela H (2020) Discovery of coesite from the martian shergottite Northwest Africa 8657. Geochim et Cosmochim Acta 286:404-17

Huffman AR, Brown JM, Carter NL, Reimold WU (1993) The microstructural response of quartz and feldspar under shock loading at variable temperatures. J Geophys Res Solid Earth 98(B12):22171-22197

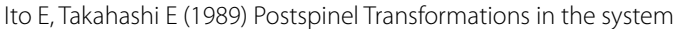
$\mathrm{Mg}_{2} \mathrm{SiO}_{4}-\mathrm{Fe}_{2} \mathrm{SiO}_{4}$ and some geophysical implications. J Geophys Res 94:10637-10646

Jeanloz R (1980) Shock effects in olivine and implications for Hugoniot data. J Geophys Res Solid Earth 85(B6):3163-3176

Jeanloz R (1989) Shock wave equation of state and finite strain theory. J Geophys Res Solid Earth 94(B5):5873-5886

Jones AH, Isbell WM, Maiden CJ (1966) Measurement of the very-highpressure properties of materials using a light-gas gun. J Appl Phys 37(9):3493-3499

Kieffer SW, Schaal RB, Gibbons R, Horz R, Milton DJ, Dube A (1976) Shocked basalt from Lonar impact crater, India, and experimental analogues. In: Proceedings of 7th lunar planet science conference, pp 1391-412

Kimura M, Chen M, Yoshida Y, El Goresy A, Ohtani E (2003) Back-transformation of high-pressure phases in a shock melt vein of an $\mathrm{H}$-chondrite during atmospheric passage: Implications for the survival of high-pressure phases after decompression. Earth Planet Sci Lett 217:141-150

Kubo T, Kimura M, Kato T, Nishi M, Tominaga A, Kikegawa T, Funakoshi K (2010) Plagioclase breakdown as an indicator for shock conditions of meteorites. Nat Geosci 3(1):41-45

Kubo T, Kato T, Higo Y, Funakoshi K (2015) Curious kinetic behavior in silica polymorphs solves seifertite puzzle in shocked meteorite. Sci Adv 1(4):e1500075

Lagain A, Benedix GK, Servis K, Baratoux D, Doucet LS, Rajšic A, Devillepoix HAR, Bland PA, Towner MC, Sansom EK, Miljković K (2021) The Tharsis mantle source of depleted shergottites revealed by 90 million impact craters. Nat Commun 12:6352

Langenhorst F, Poirier J-P (2000) 'Eclogitic' minerals in a shocked basaltic meteorite. Earth Planet Sci Lett 176:259-265

Leroux H, Reimold W, Koeberl C, Hornemann U, Doukhan J-C (1999) Experimental shock deformation in zircon: a transmission electron microscopic study. Earth Planet Sci Lett 169(3-4):291-301 
Li S, Hsu W (2018) The nature of the L chondrite parent body's disruption as deduced from high-pressure phases in the Sixiangkou L6 chondrite. Meteorit Planet Sci 53:2107-2121

Lockridge J (2015) Using Micro-Scale Observations to Understand LargeScale Geophysical Phenomena: Examples from Seismology and Mineral Physics. Dissertation, Arizona State University

Luo S-N, Mosenfelder JL, Asimow PD, Ahrens TJ (2002) Direct shock wave loading of Stishovite to 235 GPa: Implications for perovskite stability relative to an oxide assemblage at lower mantle conditions. Geophys Res Lett 29(14):36-41

Luo S-N, Ahrens TJ, Asimow PD (2003) Polymorphism, superheating, and amorphization of silica upon shock wave loading and release. J Geophys Res Solid Earth 108(B9):2421

Ma C, Tschauner O, Beckett JR, Liu Y, Rossman GR, Sinogeikin SV, Smith JS, Taylor LA (2016) Ahrensite, $y$ - $\mathrm{Fe}_{2} \mathrm{SiO}_{4}$, a new shock-metamorphic mineral from the Tissint meteorite: Implications for the Tissint shock event on Mars. Geochim Cosmochim Acta 184:240-256

Malavergne V, Guyot F, Benzerara K, Martinez I (2001) Description of new shock-induced phases in the Shergotty, Zagami, Nakhla and Chassigny meteorites. Meteorit Planet Sci 36(10):1297-1305

Marsh SP (1980) LASL shock Hugoniot data. University of California Press, Berkeley

McQueen RG (1989) Shock Waves in Condensed Media: Their Properties and the Equations of State of Materials Derived from Them. Los Alamos National Lab Report, Los Alamos, NM, USA

Melosh HJ (1989) Impact cratering: a geologic process. Oxford University Press, Oxford

Milton DJ, De Carli PS (1963) Maskelynite: formation by explosive shock. Science 140(3567):670-671

Miyahara M, Ohtani E, Kimura M, Ozawa S, Nagase T, Nishijima M, Hiraga K (2011a) Evidence for multiple dynamic events and subsequent decompression stage recorded in a shock vein. Earth Planet Sci Lett 307(3-4):361-368

Miyahara M, Ohtani E, Ozawa S, Kimura M, El Goresy A, Sakai T, Nagase T, Hiraga K, Hirao N, Ohishi Y (2011b) Natural dissociation of olivine to $(\mathrm{Mg}, \mathrm{Fe}) \mathrm{SiO}_{3}$ perovskite and magnesiowüstite in a shocked Martian meteorite. Proc Natl Acad Sci 108:5999-6003

Miyahara M, Ozawa S, Ohtani E, Kimura M, Kubo T, Sakai T, Nagase T, Nishijima M, Hirao N (2013) Jadeite formation in shocked ordinary chondrites. Earth Planet Sci Lett 373:102-108

Miyahara M, Ohtani E, El Goresy A, Ozawa S, Gillet P (2016) Phase transition processes of olivine in the shocked Martian meteorite Tissint: Clues to origin of ringwoodite-, bridgmanite- and magnesiowüstite-bearing assemblages. Phys Earth Planet Inter 259:18-28

Miyahara M, Ohtani E, Nishijima M, El Goresy A (2019) Olivine melting at high pressure condition in the chassignite Northwest Africa 2737. Phys Earth Planet Inter 291:1-11

Moreau J, Kohout T, Wünnemann K (2017) Shock-darkening in ordinary chondrites: Determination of the pressure-temperature conditions by shock physics mesoscale modeling. Meteorit Planet Sci 52(11):2375-2390

Moreau J-G, Kohout T, Wünnemann K (2018) Melting efficiency of troilite-iron assemblages in shock-darkening: Insight from numerical modeling. Phys Earth Planet Inter 282:25-38

Navrotsky A (1994) Physics and chemistry of earth materials. Cambridge University Press, Cambridge

Ohtani E, Kimura Y, Kimura M, Takata T, Kondo T, Kubo T (2004) Formation of highpressure minerals in shocked L6 chondrite Yamato 791384: constraints on shock conditions and parent body size. Earth Planet Sci Lett 227:505-515

Ostertag R (1983) Shock experiments on feldspar crystals. J Geophys Res Solid Earth 88(S01):B364-B376

Pang R-L, Zhang A-C, Wang S-Z, Wang R-C, Yurimoto H (2016) High-pressure minerals in eucrite suggest a small source crater on Vesta. Sci Rep 6:26063

Reynard B, Takir F, Guyot F, Gwanmesia G, Liebermann R, Gillet P (1996) Hightemperature Raman spectroscopic and $\mathrm{X}$-ray diffraction study of betaMg2SiO4: insights into its high-temperature thermodynamic properties and the beta-to alpha-phase-transformation mechanism and kinetics. Am Mineral 81:585-594

Richet P, Fiquet G (1991) High-temperature heat capacity and premelting of minerals in the system MgO-CaO- $\mathrm{Al}_{2} \mathrm{O}_{3}-\mathrm{SiO}_{2}$. J Geophys Res Solid Earth 96(B1):445-456
Rubin AE (1992) A shock-metamorphic model for silicate darkening and compositionally variable plagioclase in CK and ordinary chondrites. Geochim Cosmochim Acta 56:1705-1714

Rubin AE (2002) Post-shock annealing of Miller Range 99301 (LL6): Implications for impact heating of ordinary chondrites. Geochim Cosmochim Acta 66(18):3327-3337

Rubin AE (2004) Postshock annealing and postannealing shock in equilibrated ordinary chondrites: implications for the thermal and shock histories of chondritic asteroids. Geochim Cosmochim Acta 68:673-689

Ruoff AL (1967) Linear Shock-Velocity-Particle-Velocity Relationship. J Appl Phys 38(13):4976-4980

Schmitt RT, Deutsch A, Stöffler D (1994) Calculation of hugoniot curves and postshock temperatures for $\mathrm{H}$ - and L-chondrites. LPSC XXV, Houston, p 1209

Sekine T, Kobayashi T, Nishio M, Takahashi E (2008) Shock equation of state of basalt. Earth Planets Space 60(9):999-1003

Sharp TG, DeCarli PS (2006) Shock effects in meteorites. In: Lauretta DS, McSween HY (eds) Meteorid early solid system II. The University of Arizona Press, Tucson, pp 653-677

Sharp TG, Lingemann CM, Dupas C, Stöffler D (1997) Natural occurrence of $\mathrm{MgSiO}_{3}$-ilmenite and evidence for $\mathrm{MgSiO}_{3}$-perovskite in a shocked $\mathrm{L}$ chondrite. Science 277:352-355

Sharp TG, Xie Z, DeCarli PS, Hu J (2015) A large shock vein in L chondrite Roosevelt county 106: evidence for a long-duration shock pulse on the $L$ chondrite parent body. Meteorit Planet Sci 50(11):1941-1953

Sharp TG, Walton EL, Hu J, Agee C (2019) Shock conditions recorded in NWA 8159 martian augite basalt with implications for the impact cratering history on Mars. Geochim Cosmochim Acta 246:197-212

Stöffler D (1972) Deformation and transformation of rock-forming minerals by natural and experimental shock processes. I. Behavior of minerals under shock compression. Fortschritte Mineral 49:50-113

Stöffler D (1974) Deformation and transformation of rock-forming minerals by natural and experimental shock processes: II. Physical properties of shocked minerals. Fortschritte Mineral 51:256-289

Stöffler D (1984) Glasses formed by hypervelocity impact. J Non-Cryst Solids 67(1-3):465-502

Stöffler D, Ostertag R, Jammes C, Pfannschmidt G, Gupta PRS, Simon SB, Papike JJ, Beauchamp RH (1986) Shock metamorphism and petrography of the Shergotty achondrite. Geochim Cosmochim Acta 50(6):889-903

Stöffler D, Keil K, Scott ERD (1991) Shock metamorphism of ordinary chondrites. Geochim Cosmochim Acta 55:3845-3867

Stöffler D, Langenhorst F (1994) Shock metamorphism of quartz in nature and experiment: I. Basic observation and theory*. Meteoritics 29(2):155-181

Stöffler D, Hamann C, Metzler K (2018) Shock metamorphism of planetary silicate rocks and sediments: proposal for an updated classification system. Meteorit Planet Sci 53(1):5-49

Suzuki I (1975) Thermal expansion of periclase and olivine, and their anharmonic properties. J Phys Earth 23(2):145-159

Syono Y, Goto T, Takei H, Tokonami M, Nobugai K (1981) Dissociation Reaction in Forsterite under Shock Compression. Science 214(4517):177-179

Takenouchi A, Mikouchi T, Kobayashi T, Sekine T, Yamaguchi A, Ono H (2019) Fine-structures of planar deformation features in shocked olivine: A comparison between Martian meteorites and experimentally shocked basalts as an indicator for shock pressure. Meteorit Planet Sci 54(9):1990-2005

Thiéblot L, Roux J, Richet P (1998) High-temperature thermal expansion and decomposition of garnets. Eur J Mineral 10:7-16

Tomioka N, Fujino K (1997) Natural (Mg, Fe)SiO ${ }_{3}$-ilmenite and -perovskite in the Tenham meteorite. Science 277:1084-1086

Tomioka N, Miyahara M (2017) High-pressure minerals in shocked meteorites. Meteorit Planet Sci 52(9):2017-2039

Tomioka N, Kondo H, Kunikata A, Nagai T (2010) Pressure-induced amorphization of albitic plagioclase in an externally heated diamond anvil cell. Geophys Res Lett 37(21):L21301

Trønnes RG, Frost DJ (2002) Peridotite melting and mineral-melt partitioning of major and minor elements at 22-24.5 GPa. Earth Planet Sci Lett 197(1):117-131

Tschauner O, Asimow PD, Kostandova N, Ahrens TJ, Ma C, Sinogeikin S, Liu Z, Fakra S, Tamura N (2009) Ultrafast growth of wadsleyite in shock-produced melts and its implications for early solar system impact processes. Proc Natl Acad Sci 106:13691-13695 
Tschauner O, Ma C, Beckett JR, Prescher C, Prakapenka VB, Rossman GR (2014) Discovery of bridgmanite, the most abundant mineral in Earth, in a shocked meteorite. Science 346(6213):1100-1102

Tyburczy JA, Xu X, Ahrens TJ, Epstein S (2001) Shock-induced devolatilization and isotopic fractionation of $\mathrm{H}$ and $\mathrm{C}$ from Murchison meteorite: some implications for planetary accretion. Earth Planet Sci Lett 192(1):23-30

Walsh JM, Christian RH (1955) Equation of state of metals from shock wave measurements. Phys Rev 97(6):1544-1556

Walton EL (2013) Shock metamorphism of Elephant Moraine A79001: Implications for olivine-ringwoodite transformation and the complex thermal history of heavily shocked Martian meteorites. Geochim Cosmochim Acta 107:299-315

Walton EL, Herd CDK (2007) Localized shock melting in Iherzolitic shergottite Northwest Africa 1950: Comparison with Allan Hills 77005. Meteorit Planet Sci 42(1):63-80

Walton EL, Sharp TG, Hu J, Filiberto J (2014) Heterogeneous mineral assemblages in martian meteorite Tissint as a result of a recent small impact event on Mars. Geochim Cosmochim Acta 140:334-348

Waples DW, Waples JS (2004) A review and evaluation of specific heat capacities of rocks, minerals, and subsurface fluids. Part 1: minerals and nonporous rocks. Nat Resour Res 13(2):97-122

Watanabe $\mathrm{H}$ (1982) Thermochemical properties of synthetic high-pressure compounds relevant to the Earth's mantle. High-Press Res Geophys 12:441-464

Xie Z, Sharp TG (2004) High-pressure phases in shock-induced melt veins of the Umbarger L6 chondrite: constraints of shock pressure. Meteorit Planet Sci 39:2043-2054

Xie Z, Sharp TG (2007) Host rock solid-state transformation in a shock-induced melt vein of Tenham L6 chondrite. Earth Planet Sci Lett 254:433-445

Xie Z, Sharp TG, DeCarli PS (2006a) Estimating shock pressures based on highpressure minerals in shock-induced melt veins of $L$ chondrites. Meteorit Planet Sci 41:1883-1898

Xie Z, Sharp TG, DeCarli PS (2006b) High-pressure phases in a shock-induced melt vein of the Tenham L6 chondrite: Constraints on shock pressure and duration. Geochim Cosmochim Acta 70:504-515

Xing W, Lin Y, Zhang C, Zhang M, Hu S, Hofmann BA, Sekine T, Xiao L, Gu L (2020) Discovery of Reidite in the Lunar Meteorite Sayh al Uhaymir 169. Geophys Res Lett 47(21):e2020GL089583

Yolcubal I, Sack RO, Wang M-S, Lipschutz ME (1997) Formation conditions of igneous regions in ordinary chondrites: Chico, Rose City, and other heavily shocked H and L chondrites. J Geophys Res Planets 102(E9):21589-21611

Zhang J, Herzberg C (1994) Melting experiments on anhydrous peridotite KLB-1 from 5.0 to 22.5 GPa. J Geophys Res Solid Earth 99:17729-17742

\section{Publisher's Note}

Springer Nature remains neutral with regard to jurisdictional claims in published maps and institutional affiliations.

\section{Submit your manuscript to a SpringerOpen ${ }^{\circ}$ journal and benefit from:}

- Convenient online submission

- Rigorous peer review

- Open access: articles freely available online

- High visibility within the field

- Retaining the copyright to your article

Submit your next manuscript at $\boldsymbol{\nabla}$ springeropen.com 